OPEN ACCESS

Edited by:

Aldo R. Boccaccini,

University of Erlangen Nuremberg,

Germany

Reviewed by:

Pamela Habibovic,

Maastricht University, Netherlands

Shun Duan,

Beijing University of Chemical

Technology, China

*Correspondence:

Yi Zhang

zhangyizmr@163.com

Xin Wang

Ichwx@aliyun.com

these authors have contributed equally to this work and share first authorship

Specialty section:

This article was submitted to

Biomaterials,

a section of the journal

Frontiers in Materials

Received: 24 April 2021 Accepted: 05 July 2021

Published: 15 July 2021

Citation:

Lu H, Zhou Y, Ma Y, Xiao L, Ji W, Zhang $Y$ and Wang $X$ (2021) Current

Application of Beta-Tricalcium

Phosphate in Bone Repair and lts Mechanism to Regulate Osteogenesis.

Front. Mater. 8:698915

doi: 10.3389/fmats.2021.698915

\section{Current Application of Beta-Tricalcium Phosphate in Bone Repair and Its Mechanism to Regulate Osteogenesis}

\author{
Haiping $\mathrm{Lu}^{1,2 t}$, Yinghong Zhou ${ }^{3 t}$, Yaping $\mathrm{Ma}^{1,2}$, Lan Xiao ${ }^{3}$, Wenjun $\mathrm{Ji}^{1}$, Yi Zhang ${ }^{4,2 *}$ and \\ Xin Wang ${ }^{1,3,2 * t}$
}

\begin{abstract}
${ }^{1}$ Department of Orthopaedic Surgery, Affiliated Hospital of Zunyi Medical University, Zunyi, China, ${ }^{2}$ Joint Orthopaedic Research Center of Zunyi Medical University \& University of Rochester Medical Center (JCMR-ZMU \& URMC), Zunyi Medical University, Zunyi, China, ${ }^{3}$ Institute of Health and Biomedical Innovation, Queensland University of Technology, Brisbane, QLD, Australia, ${ }^{4}$ Department of Hygiene Toxicology, School of Public Health, Zunyi Medical University, Zunyi, China
\end{abstract}

Large segmental bone loss and bone resection due to trauma and/or the presence of tumors and cysts often results in a delay in healing or non-union. Currently, the bone autograft is the most frequently used strategy to manage large bone loss. Nevertheless, autograft harvesting has limitations, namely sourcing of autograft material, the requirement of an invasive procedure, and susceptibility to infection. These disadvantages can result in complications and the development of a bone substitute materials offers a potential alternative to overcome these shortcomings. Among the biomaterials under consideration to date, beta-tricalcium phosphate ( $\beta$-TCP) has emerged as a promising material for bone regeneration applications due to its osteoconductivity and osteoinductivity properties as well as its superior degradation in vivo. However, current evidence suggests the use $\beta$-TCP can in fact delay bone healing and mechanisms for this observation are yet to be comprehensively investigated. In this review, we introduce the broad application of $\beta$-TCP in tissue engineering and discuss the different approaches that $\beta$-TCP scaffolds are customized, including physical modification (e.g., pore size, porosity and roughness) and the incorporation of metal ions, other materials (e.g., bioactive glass) and stem cells (e.g., mesenchymal stem cells). 3D and 4D printed $\beta$-TCP-based scaffolds have also been reviewed. We subsequently discuss how $\beta$-TCP can regulate osteogenic processes to aid bone repair/healing, namely osteogenic differentiation of mesenchymal stem cells, formation of blood vessels, release of angiogenic growth factors, and blood clot formation. By way of this review, a deeper understanding of the basic mechanisms of $\beta$-TCP for bone repair will be achieved which will aid in the optimization of strategies to promote bone repair and regeneration.

Keywords: beta-tricalcium phosphate, bone fractures, early bone healing, fracture hematoma, osteogenesis 


\section{INTRODUCTION}

Large bone loss as a result of trauma, tumor removal, infection, and developmental congenital disorders, often leads to delayed healing or non-union, and remains a critical challenge for orthopedic surgeons. Until recently, the standard clinical management to facilitate bone healing was the use of a bone autograft (Zheng et al., 2018). Still, the drawbacks of this technique, such as limited autogenous bone source and potential complications necessitates other bone substitutes for clinical use to be evaluated (Robering et al., 2020). The main challenge for large bone defect repair and regeneration remains the inadequate recruitment of mesenchymal stem cells (MSCs), reduced vascularization, and decreased growth factors stimulation within the scaffold construct to support cell viability and tissue growth. Consequently, enhancing the adhesion of MSCs, augmenting the release of growth factors, and promoting angiogenic potential of biomaterial scaffolds after implantation are pivotal for successful bone regeneration.

Beta-tricalcium phosphate $(\beta-\mathrm{TCP})$ is a bioceramic material favored by orthopedic surgeons for bone repair due to its exceptional biocompatibility and bioactivity (Kang et al., 2020). Application of $\beta$-TCP alone can significantly increase bone regeneration in bone defect animal models compared with nanostructured carbon implants and porous titanium (Gilev et al., 2019) and studies suggest $\beta$-TCP can significantly enhance bone regeneration compared with bone autografts (Pereira et al., 2017). To create a favorable osteogenic environment, $\beta$-TCP scaffolds have been modified in a number of ways to boost bone healing, including modulating physical features (e.g., pore sizes, porosity and surface roughness), combining with ionic components, and the addition/delivery of growth factors.

However, conflicting results indicate the clinical use of $\beta$-TCP for bone repair remains questionable in several specific experiment models. For example, implantation of $\beta$-TCP into critical size circumferential defects of sheep ilium demonstrated significantly reduced new bone formation $(1.1 \% \pm 0.5)$ compared with control $(11 \% \pm 2.9)$, suggesting $\beta$-TCP may contribute to delayed healing (Choo et al., 2013). Furthermore, in a rat mandibular defect model, a delay in early bone healing compared to control was observed when $\beta$-TCP particles were applied locally (Wang et al., 2018a). One possible explanation for a $\beta$-TCP-mediated delay in bone healing could be the accelerated formation of fine fibers within blood clots as a consequence of $\mathrm{Ca}^{2+}$ and $\mathrm{PO}_{4}{ }^{3-}$ ions released by $\beta$-TCP. Consequently, this may hinder early recruitment of MSCs for bone repair and regeneration.

These conflicting results surrounding $\beta$-TCP-mediated bone healing therefore warrant further investigation and evaluation of the clinical application of $\beta$-TCP for bone defect repair. It has been demonstrated that $\mathrm{Ca}^{2+}$ released from $\beta$-TCP plays a crucial role in the proliferation and differentiation of MSCs and osteoblasts (Lei et al., 2018). Since the release of $\mathrm{Ca}^{2+}$ is closely linked to the process of neovascularization in the fracture site, and blood clot structure at the fracture site is critical for bone healing, it is possible that $\mathrm{Ca}^{2+}$ released from $\beta$-TCP affects blood clot structure thus delaying bone regeneration. This review therefore focuses on the latest developments in $\beta$-TCP materials, the impact of its features on bone regeneration, and the role of $\beta$-TCP in blood clot formation and the initial stage of bone healing.

\section{THE INFLUENCE OF PHYSICAL PROPERTIES OF BETA-TRICALCIUM PHOSPHATE ON OSTEOGENESIS}

The physical characteristics of implanted biomaterials can affect the proliferation rate of osteoblasts and has important effects on cytokine gene expression (Barbeck et al., 2021). It has been established that the porous structure of calcium phosphate material can significantly influence bone regeneration (Xie et al., 2016; Bastami et al., 2017; Seong et al., 2020; Zamani et al., 2021). The porous surface of bone materials enhances the mechanical interlocking between the bone substitute and the surrounding bone tissues, providing mechanical stability to the bone-material interface (Meka et al., 2019; Roopavath et al., 2019; Cao et al., 2019; Dos Santos Trento et al., 2020). Two different range of pore sizes have generally been studied: micropore $(<5 \mu \mathrm{m}$ in diameter) and macropore $(>100 \mu \mathrm{m}$ in diameter) (Blokhuis et al., 2000). The presence of micropores increase in the surface area of biomaterials while micropore structures have been demonstrated to enhance material resorption and boost osteoinduction (Davison et al., 2014; Rustom et al., 2019). Open and interconnected macropores are not only useful for cell migration and blood vessel formation, but also essential for the diffusion of nutrients, waste and pro-osteogenic factors (Loh and Choong, 2013; Lim et al., 2020). Therefore, porosity not only allows biomaterials to absorb growth factors, but also controls the complex interaction between bone materials and pro-osteogenic factors (e.g., bone morphogenetic proteins). In a femur defect model of rabbit, the honeycomb $\beta$-TCP scaffolds with interconnected pore structure (ihTCP) presented higher new bone formation volume compared to the unidirectional pore structure (uhTCP) (Lu et al., 2020a). Studies have demonstrated that materials with high porosity have a positive impact on bone formation (Hannink and Arts, 2011; Raeisdasteh Hokmabad et al., 2017; Ishikawa et al., 2018). Similarly, porous $\beta$-TCP has the ability to augment the dissolution and absorption of the material and boost the infiltration of MSCs, thus enhancing new bone formation (Karageorgiou and Kaplan, 2005; Lopez-Heredia et al., 2012). An in vitro study showed that murine osteoblast precursors (MC3T3-E1) and human adipose stem cells (hADSCs) exhibited excellent proliferation and osteogenic differentiation when seeded into porous $\beta$-TCP blocks (Kim and Kim et al., 2019). Furthermore, when $\beta$-TCP blocks with $58.1 \pm 1.7 \%$ porosity were implanted into rabbit distal femoral bone defects for 4 weeks, the amount of newly formed bone in porous $\beta$-TCP blocks group was approximately 200-fold higher compared with the dense $\beta$-TCP blocks group (with $10.9 \pm 2.3$ porosity) (Putri et al., 2020). In a study operating Opening-Wedge High Tibial Osteotomy in 25 patients, $\beta$-TCP blocks with $60 \%$ porosity showed a superior bone formation compared to the $\beta$-TCP blocks with $75 \%$ porosity (Tanaka et al., 2008). To sum up, the suitable porosity of $\beta$-TCP block to boost bone regeneration is approximately $60 \%$.

Surface roughness is a factor that influences cellular attachment and subsequent bone repair (Albrektsson and 


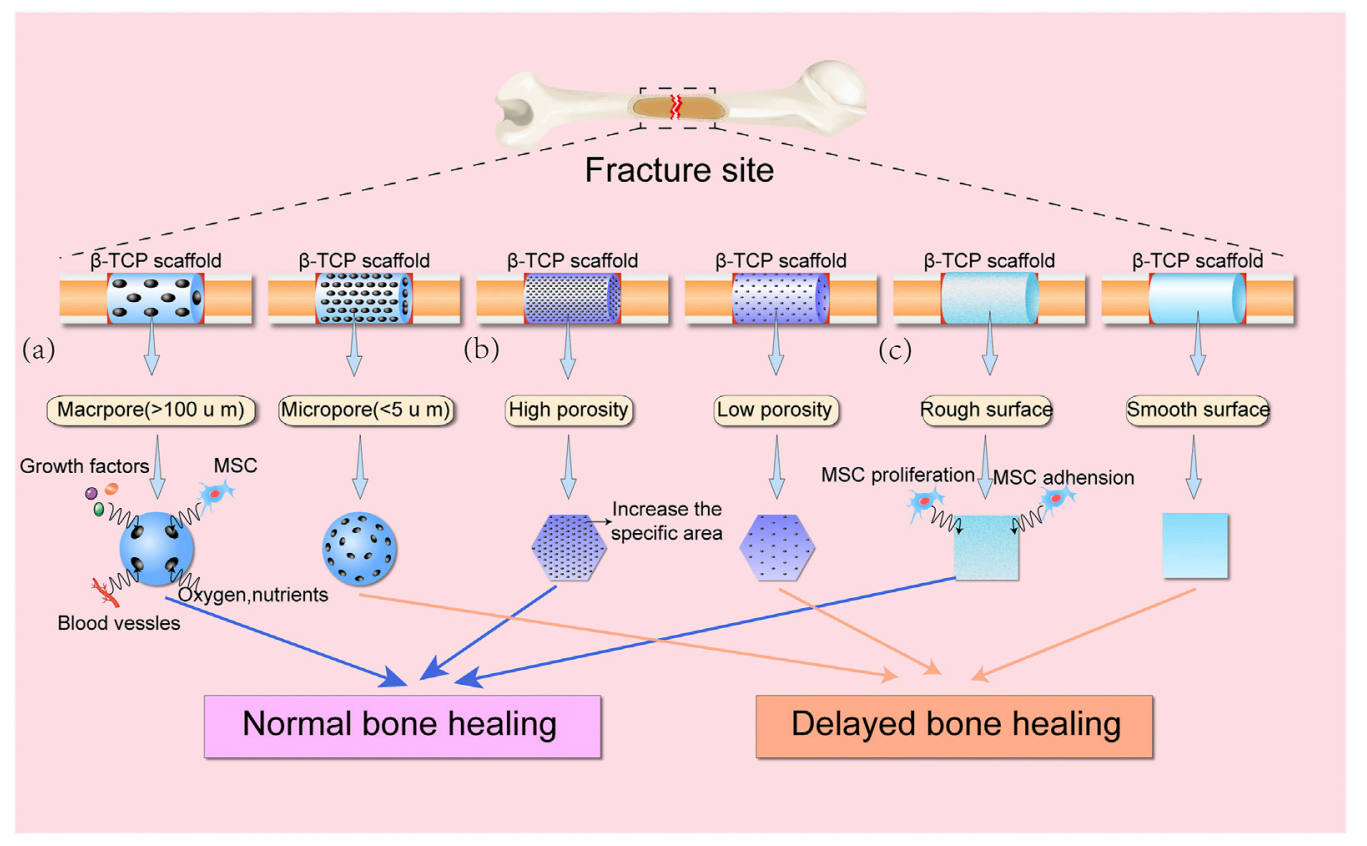

FIGURE 1 | Schematic diagram showing the effects of various physical features of $\beta$-TCP scaffolds on bone healing. (A) Macropores (>100 $\mu \mathrm{m})$ provide greater space for access of growth factors, MSCs, blood vessels, oxygen, and nutrients into $\beta$-TCP scaffolds compared with micropores (<5 $\mu$ m). (B) High porosity can significantly increase the specific areas of $\beta$-TCP scaffolds, as compared to $\beta$-TCP scaffolds with low porosity. (C) Rough surface of $\beta$-TCP scaffolds can improve MSC adhesion and proliferation, thereby promoting bone regeneration.

Johansson, 2001; Faia-Torres et al., 2015; Dantas et al., 2017; Dong et al., 2020). Materials with a high surface roughness can enhance the attachment of bone-forming cells, thereby promoting osteogenic differentiation and osteointegration, while low surface roughness may result in integration failure due to inferior cell attachment. It has been demonstrated that 8-10 arithmetical roughness average ( $\mathrm{Ra}$ ) calcium phosphatecoated titanium alloy showed a superior adhesion capacity of type I collagen compared with a 2-3 Ra calcium phosphate-coated surface (Ozerdem 2002). Additionally, using argon glow discharge plasma (GDP) to modify the surface of $\beta$-TCP can remove macro and micro particles of $<7 \mu \mathrm{m}$ in size from $\beta$-TCP bigger particles surface thus promoting human mesenchymal stem cells (hMSCs) proliferation, osteoblastic differentiation, and increasing more new bone formation compared to the untreated $\beta$-TCP block (Choy et al., 2021). These results suggest that the porous structure and surface roughness of $\beta$-TCP-based materials can be optimized to enhance new bone formation. Furthermore, pores of different sizes can be adjusted to facilitate protein adsorption, cell infiltration and neovascularization (Figure 1).

\section{METAL ION/ESSENTIAL ELEMENT - INCORPORATED BETA-TRICALCIUM PHOSPHATE COMPLEX}

In addition to modulating the physical features of $\beta$-TCP, the incorporation of metal ions can improve the osteoinductive capacity of $\beta$-TCP scaffolds. The release of metal ions, such as cobalt $\left(\mathrm{Co}^{2+}\right)$, copper $\left(\mathrm{Cu}^{2+}\right)$, and magnesium $\left(\mathrm{Mg}^{2+}\right)$, and essential elements, such as zinc $\left(\mathrm{Zn}^{2+}\right)$ and silicon $\left(\mathrm{Si}^{4+}\right)$ can enhance the biological performance of bone regenerative scaffolds, which can induce angiogenesis and osteogenesis (Wang, et al. 2017a). Previous studies have demonstrated that metal ions can be easily incorporated into $\beta$-TCP (Matsunaga et al., 2015). $\mathrm{Mg}^{2+}, \mathrm{Zn}^{2+}$ and other divalent cations smaller than $\mathrm{Ca}^{2+}$ can preferentially substitute the $\mathrm{Ca}(4)$ and $\mathrm{Ca}(5)$ cation sites in $\beta$-TCP. However, larger divalent cations such as strontium $\left(\mathrm{Sr}^{2+}\right)$ preferentially reside in sites $\mathrm{Ca}$ (1)-Ca (4), but not $\mathrm{Ca}$ (5) (Enderle et al., 2005; Ji et al., 2014). Mono- and trivalent cations tends to occupy $\mathrm{Ca}^{2+}$ on the partially occupied $\mathrm{Ca}(4)$ site. $\mathrm{Si}^{4+}$ is an alternative cation of $\mathrm{P}^{5+}$ on the tetrahedral sites in the $\mathrm{PO}_{4}$ groups (Reid et al., 2005).

The addition of certain metal ions can lead to favorable effects on bone regeneration. For example, $\mathrm{Co}^{2+}$-containing $\beta$-TCP composite scaffolds (CCP) can significantly induce the expression of osteogenic marker genes (ALP, OCN and IBSP) in human MSCs (hMSCs) compared with unmodified $\beta$-TCP scaffolds (Chen et al., 2015a). Similar findings have been demonstrated with the application of $\mathrm{Cu}^{2+}$, which could enhance the osteogenic and angiogenic capacities of $\beta$-TCP powders (Zhang et al., 2019). This can be explained by the hypoxia-mimicking microenvironment induced by $\mathrm{Co}^{2+}$ and $\mathrm{Cu}^{2+}$. The stabilization of hypoxia inducible factor 1-a (HIF1a) can stimulate the endogenous release of angiogenic growth factors from the surrounding cells, which initiate the ingrowth of new blood vessels from host tissues, further facilitating 
osteogenesis via the angiogenesis-osteogenesis coupling (Krock et al., 2011; Zhao et al., 2021).

$\mathrm{Mg}^{2+}$ is a known activator for phosphate-transferring enzymes (Gu et al., 2019) with Mg-doped bone substitute biomaterials able to regulate bone metabolism and facilitate bone regeneration by inducing a significant increase in osteogenic differentiation of MSCs (Wang and Yeung, 2017). An in vitro study demonstrated cell proliferation and viability of human bone marrow-derived MSCs (hBMSCs) and human umbilical vein endothelial cells (HUVECs) were significantly enhanced when treated with $\mathrm{Mg}$ doped $\beta$-TCP scaffolds, compared with control $\beta$-TCP scaffolds (Gu et al., 2019). And $\mathrm{Mg}^{2+}$ in $\beta$-TCP/Mg-Zn composite scaffold was demonstrated to promote the differentiation of hBMSCs into osteoblasts via mitogen activated protein kinases (MAPKs)regulated Runx2/Osterix (Osx) interaction (Wang et al., 2020a). However, in a murine dental alveolus grafting model, Mg-doped $\beta$-TCP granules scaffolds presented lower biosorption and less newly formed bone compared with the $\beta$-TCP group $(p<$ 0.05) (Yassuda et al., 2013). The most plausible explanation for this is $\mathrm{Mg}^{2+}$ incorporation into $\beta$-TCP granules reduces resorption by downregulating parathormone (PTH) production in vivo, thereby inhibiting osteogenesis (Yassuda et al., 2013).

Zinc and silicon are two essential elements that have been widely studied to improve the osteoinductivity of $\beta$-TCP for osteogenesis. An in vitro study clearly demonstrated that both zinc oxide $(\mathrm{ZnO})$-doped $\beta$-TCP ( $\mathrm{Zn}$-TCP) and silicon oxide $\left(\mathrm{SiO}_{2}\right)$ doped $\beta$-TCP (Si-TCP) scaffolds could improve the expression of osteogenic marker genes, such as BMP-2, and Runx2 compared with the unmodified $\beta$-TCP group (Fielding et al., 2019). Moreover, in a rabbit tibial defect model, a significant increase in new bone formation was observed in $\mathrm{ZnO}$ - and $\mathrm{SiO}_{2}$ doped $\beta$-TCP scaffold groups compared with the $\beta$-TCP control group (Nandi et al., 2018). A plausible explanation for this effect is that $\mathrm{Si}^{4+}$ replaces $\mathrm{P}^{5+}$ in the $\beta$-TCP lattice, and $\mathrm{Zn}^{2+}$ replaces $\mathrm{Ca}^{2+}$. The released $\mathrm{Ca}^{2+}$ ions can therefore enhance the expression of osteogenesis-related genes through the activation of intracellular calcium and Wnt signaling (Majidinia et al., 2018; Martineau et al., 2017).

The incorporation of $10 \mathrm{wt} \%$ manganese ion $\left(\mathrm{Mn}^{2+}\right)$ doped $\beta$-tricalcium phosphate (Mn-TCP) into calcium phosphate cement (CPC) has proper physicochemical properties and exhibits higher ability to promote osteogenic differentiation in vitro compared to the control group (0 wt\% $\mathrm{Mn}$-TCP-CPC), $20 \mathrm{wt} \% \mathrm{Mn}-\mathrm{TCP}-\mathrm{CPC}$ group and $30 \mathrm{wt} \% \mathrm{Mn}-\mathrm{TCP}-\mathrm{CPC}$ group (Wu et al., 2020). Nanosized-Ag-doped porous $\beta$-TCP scaffolds facilitate new bone formation and exhibits superior anti-infective properties as compared to pure $\beta$-TCP group, when tested in a rabbit femoral bone defect model (Yuan et al., 2020).

\section{BETA-TRICALCIUM PHOSPHATE IN COMBINATION WITH OTHER MATERIALS}

The degradation rate of $\beta$-TCP leaves insufficient time for osteoblast migration and colonization, impairing normal bone healing and limiting its clinical application (Pilliar et al., 2001). To address this problem, other materials have been combined with $\beta$-TCP to form composite scaffolds with superior biomechanical properties. In a recent study, $\beta$-TCP mixed with hydroxyapatite (HA) composite scaffolds (BCP) showed a remarkable increase in compressive strength $(1.7 \mathrm{MPa})$ compared with normal $\beta$-TCP scaffolds (1.2 MPa) (Stastny et al., 2019). Moreover, the BCP scaffolds presented a steady and moderate degradation rate with a compressive strength of $0.5 \mathrm{MPa}$ in the presence of an acidic buffer solution ( $\mathrm{pH}=5.5$ ), which was demonstrated to be more beneficial for hMSCs adhesion, proliferation, and bone metabolism activity (Stastny et al., 2019). Furthermore, Cheng et al fabricated $25 \%$ collagen- $15 \%$ thermosensitive hydrogel- $60 \%$ $\beta$-TCP (CTC) composite scaffolds, which were showed to have better mechanical properties, osteoinductivity and weightbearing capacity than $70 \%$ HA/30\% $\quad \beta$-TCP composite scaffolds when implanted into tibia defect in mice (Cheng et al., 2021).

An in vitro study found that a composite scaffold comprised of $30 \% \beta$-TCP and $70 \%$ bioactive glass (BG) stimulated the proliferation of osteoblast-like MG-63 cells, compared with the $\beta$-TCP group (Seidenstuecker et al., 2017). Another study found that a nano-sized $\beta$-TCP and polylactic acid (PLA) mixture presented significantly higher disc height compared to the autograft group (Cao et al., 2017). Moreover, the $\beta$-TCP-PLA mixture membrane has been demonstrated to favor bone healing in the anterior esthetic area of the maxilla in a recent clinical study (Canullo et al., 2019). It has also been revealed that $\beta$-TCPchitosan composite scaffolds can significantly enhance the proliferation and osteogenic differentiation of BMSCs in vitro (Wang et al., 2019a). Additionally, the addition of pulverized human bone into $\beta$-TCP-chitosan composite scaffolds presented excellent mechanical properties and induced significantly higher ALP activity than $\beta$-TCP-chitosan composite scaffolds when seeded with MG63 cells (Kowalczyk et al., 2021). Besides, Han et al found that the $50 \%$ PCL-50\% $\beta$-TCP spinal fusion cage had optimal osteogenic capacity as compared to 60\% PCL- $40 \%$ $\beta$-TCP and 55\% PCL-45\% $\beta$-TCP spinal fusion cage in vitro (Han et al., 2021). Although large volume of $\beta$-TCP-based composites have been developed, further clinical trials are required before applying it to the clinic.

\section{THE ADDITION OF STEM CELLS AND CELL-DERIVED ACTIVE SUBSTANCE TO BETA-TRICALCIUM PHOSPHATE}

The addition of stem cells or cell-derived active substance, such as exosomes and extracellular matrix (ECM), to $\beta$-TCP can largely improve its osteogenic properties (Zhang et al., 2016). For example, in a monkey femur bone defect model, the ratio of successful bone union in composites containing $\beta$-TCP blocks and bone marrow mesenchymal stem cells (BMSCs) (5/7) was markedly higher compared to the $\beta$-TCP blocks alone (1/5) (Masaoka et al., 2016). In another study, $\beta$-TCP/gelatine scaffold combined with allogeneic adipose-derived stem cells (ASCs) showed a superior pro-osteogenic effect compared with $\beta$-TCP/gelatine scaffold and pure $\beta$-TCP scaffold in a 
rabbit femoral bone defect model (Liu et al., 2021). Du et al. recently revealed that bone marrow mononuclear cells (BMMNCs) $/ \beta$-TCP scaffold had a 1.5 -fold more bone volume compared to the bone marrow-derived mesenchymal stem cells (BMSCs)/ $\beta$-TCP scaffold after implanted into a tibia bone defect for 12 months (Du et al., 2021). Furthermore, in a recent clinical study, patients treated with MSC/ $\beta$-TCP composite scaffolds presented significantly more new bone formation and improved functional recovery compared with the pure $\beta$-TCP (Chu et al., 2019).

The incorporation of exosomes derived from bone mesenchymal stem cells (BMSC) and hypoxia inducible factor$1 \alpha$ (HIF-1 $\alpha)$ to $\beta$-TCP scaffolds significantly repaired rat criticalsized bone defects by facilitating new bone regeneration and neovascularization (Ying et al., 2020). Dental pulp stem cells (DPSCs)-derived extracellular vesicle (EVs)/ $\beta$-TCP scaffolds was demonstrated to boost bone formation in the periphery of the defects (Imanishi et al., 2021). Moreover, in a pig mandibular bony defect model, MSCs and platelet-rich plasma (PRP)impregnated polycaprolactone (PCL)- $\beta$-TCP bio-scaffold presented excellent ability to enhance bone regeneration around dental implants (Almansoori et al., 2021).

\section{D AND 4D PRINTED BETA-TRICALCIUM PHOSPHATE-BASED SCAFFOLDS}

It was only until recently that three-dimensional (3D) printed $\beta$-TCP-based materials were widely used in research and clinical applications due to the easily controllable size and shape. For example, the $3 \mathrm{D}$ printed $\beta$-TCP scaffolds with diverse pore size $(500,750$, and $1,000 \mu \mathrm{m})$ not only possess excellent mechanical properties, but also boost proliferation of MG-63 cells (Seidenstuecker et al., 2019). Moreover, 3D-printed polycaprolactone (PCL)/ $\beta$-TCP scaffolds showed promising potential for oromandibular reconstruction in vivo (Lee et al., 2020). However, the manufacturing process of traditional 3D printing is performed at high temperatures, which may lead to the loss of bio-efficacy of sensitive growth regulators, such as icariin (ICA) (Zhang et al., 2021). To incorporate various active growth regulators within the porous architectures of $\beta$-TCP materials, low-temperature based $3 \mathrm{D}$ printing technique is used. For example, the low-temperature extrusion-based $3 \mathrm{D}$ printing of composite scaffolds constructed by poly ( $\varepsilon$-caprolactone) (PCL) and $\beta$-TCP encapsulated with ICA (ITP scaffolds) promoted differentiation of BMSCs in vitro (Zhang et al., 2021). Though 3D-printing allows for the manufacturing of complex shapes on demand, those shapes of printed products do not change over time. The emerging $4 \mathrm{D}$ printing technology is gaining great interest because of its changeable shapes. Wang et al. constructed $\beta$-TCP-based nanocomposite scaffolds by incorporating black phosphorus nanosheets and osteogenic peptide into $\beta$-TCP/poly (lactic acid-co-trimethylene carbonate) (TCP/P (DLLA-TMC)) by $4 \mathrm{D}$ printing. The shape of the $4 \mathrm{D}$-printed scaffolds can be reconfigured to adjust precise fitting in irregular bone defects when the scaffold temperature rapidly increases to $45^{\circ} \mathrm{C}$ (Wang et al., 2020b). To date, the
$\beta$-TCP-based $4 \mathrm{D}$ printed products have rarely been reported in bone tissue engineering, however, these materials have substantial potential as bone substitutes although further research is warranted.

\section{BETA-TRICALCIUM PHOSPHATE-MEDIATED MECHANISMS FOR OSTEOGENESIS REGULATIES}

Although the pro-osteogenic effects of $\beta$-TCP remain controversial, $\beta$-TCP affect bone repair by interacting with the surrounding tissues through the regulation of growth factors, cytokines and ions. A possible mechanism of $\beta$-TCP-regulated osteogenesis is that $\beta$-TCP can directly or indirectly (via the release of ionic components such as $\mathrm{Ca}^{2+}$ and $\mathrm{PO}^{3-}$ ) facilitate osteoblast differentiation, promote vascularization, regulate the release of growth factors, and alter blood clot formation thus boosting bone healing at defect sites.

\section{The Effect of $\mathrm{Ca}^{2+}$ on Osteoblast Differentiation}

Numerous studies have confirmed the crucial role of $\mathrm{Ca}^{2+}$ released from $\beta$-TCP plays in proliferation and differentiation of MSCs and osteoblasts. It has been suggested that $2-4 \mathrm{mmol} / \mathrm{L}$ $\mathrm{Ca}^{2+}$ in vitro is favorable to the proliferation and survival of mouse primary osteoblasts (mOBs), whereas slightly higher concentrations $(6-8 \mathrm{mmol} / \mathrm{L})$ can facilitate mOBs differentiation and matrix mineralization (Maeno et al., 2005; Wang et al., 2020c). Other studies have found that a higher concentration of $\mathrm{Ca}^{2+}$ (up to $14 \mathrm{mmol} / \mathrm{L}$ ) can lead to a rounded shape osteoblast morphology while a lower concentration of $\mathrm{Ca}^{2+}$ $(\leq 8 \mathrm{mmol} / \mathrm{L})$ can promote the migration of human osteoblasts (Lei et al., 2018; Nakamura et al., 2010).

It has been suggested that $\mathrm{Ca}^{2+}$-mediated osteoblast differentiation involves the activation of the Calmodulin and Calmodulin-dependent kinase II (CaM-CaMKII) pathway (Cary et al., 2013; Liu et al., 2020). The activation of $\alpha$-CaMKII boosts autophosphorylation of threonine 286, resulting in increased affinity of CaMKII for $\mathrm{Ca}^{2+} / \mathrm{CaM}$ by nearly 1000 -fold while also maintaining the enzyme in a partially activated or autonomous state (Zayzafoon et al., 2005). The phosphorylated $\alpha$-CaMKII subsequently modulates the activity of several transcription factors, such as CRE-binding protein (CREB) and extracellular signal-regulated kinase (ERK) (Zayzafoon et al., 2005; Lu et al., 2020b) which transactivate the serum-response element (SRE) and cAMP-response element (CRE) within the promoter of $c$-fos respectively (Kukushkin et al., 2002; Sen et al., 2015). This in turn enhances expression of AP-1, a transcription factor involved in differentiation of bone forming cells and ultimately results in the differentiation of osteoblasts (Figure 2) (Wagner 2002; Babu et al., 2013). Another study suggested L-type voltage-gated calcium channels (L-VGCCs) play a role in modulating the $\mathrm{Ca}^{2+}$ released from $\beta$-TCP. Blockade of L-VGCCs with nifedipine significantly inhibited the expression of 


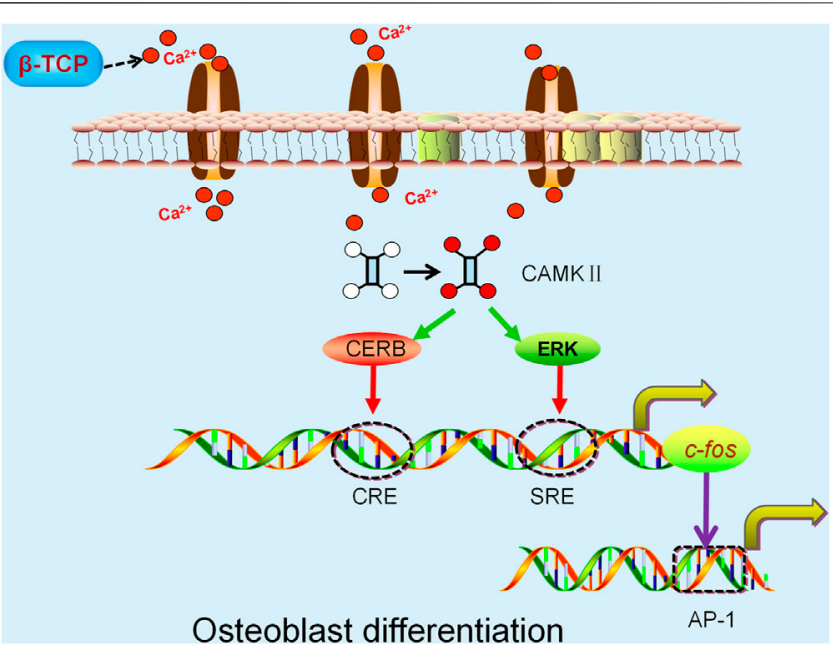

FIGURE 2 | $\beta$-TCP-released $\mathrm{Ca}^{2+}$ activates the $\alpha$-CaMKII pathway and modulates CREB and extracellular ERK activity. The activation of CRE-binding protein (CREB) and extracellular signal-regulated kinase (ERK) increase the transactivation of SRE and CRE respectively, both of which regulate the c-fos promoter resulting in enhanced expression of AP-1 and ultimately osteoblast differentiation.

the osteoblast differentiation protein, bone morphogenetic protein 2 (BMP-2), indicating that osteogenic differentiation may be regulated by L-VGCCs (Barradas et al., 2012). Similarly, another study has demonstrated inhibition of L-VGCCs can suppress the osteogenic differentiation of rat BMSCs (Wen et al., 2012). Interestingly, conflicting results have been reported using mouse BMSCs. Ma et al. demonstrated L-VGCCs treated with the blocker, benidipine enhanced mouse BMSCs differentiation by upregulating the $\mathrm{Wnt} / \beta$-catenin pathway in an ovariectomized (OVX) mouse model (Ma et al., 2015). This phenomenon is probably due to different L-VGCCs subtypes which exist in cells from different tissues and species (Tan et al., 2019).

\section{The Effect of Beta-Tricalcium Phosphate on Neovascularization}

To survive, osteoblasts (OBs) must reside within 150-200 $\mu \mathrm{m}$ of capillaries to obtain a sufficient supply of oxygen and nutrients (Nguyen et al., 2012). Conversely, inadequate angiogenesis can result in necrosis in the central region of bone tissues, and delay the bone regeneration process. Therefore, the extent and rate of vascular growth are thought to be important determinants in effective bone healing (Liu et al., 2015). $\mathrm{Ca}^{2+}$, one of the major components of $\beta$-TCP, plays a critical role in blood vessel formation. Studies over the past decade has demonstrated that intracellular $\mathrm{Ca}^{2+}$ concentration is associated with the proliferation and movement of endothelial cells. The intracellular $\mathrm{Ca}^{2+}$ wave drives proliferation, homing and tubulogenesis of endothelial progenitor cells (EPC) (Moccia et al., 2014; Moccia et al., 2012). $\mathrm{Ca}^{2+}$ exhibits a unique regulatory role in cytoplasm, organelles, and nuclei by acting as an allosteric activator or inhibitor of various intracellular enzymes. It can also interact with other proteins to regulate calcium-dependent enzymes and ion channels. The most significant example is $\mathrm{CaM}$, a $\mathrm{Ca}^{2+}$ decoder for cell proliferation that is involved in regulating the CaMKII family and several other membrane channels. Multiple studies have shown that CaMKII is directly involved in several transition points in the progress of the cell cycle (G1 to S) (Kahl and Means, 2003; Zeng et al., 2020; Koval et al., 2019). Moreover, calcium-dependent enzymes initiate the activation of several nuclear factors related to DNA division, such as cyclin, which is closely associated with the proliferation of endothelial cells ( $\mathrm{Li}$ et al., 2016; Hui et al., 2011). Vascular endothelial growth factor (VEGF), a potent regulator of vascular formation, stimulates the proliferation, migration, differentiation and formation of capillary-like structures in endothelial cells via the Ras/mitogen-activated protein kinase (Ras/MAPK), phosphatidylinositol 3-kinase (PI3K/AKT) and phospholipase $\mathrm{C} \gamma /$ inositol triphosphate (PLC $\gamma /$ IP3) signaling pathways in the presence of $\mathrm{Ca}^{2+}$ after binding to vascular endothelial growth factor receptor 2 (VEGFR2) (Jin et al., 2017; Kim et al., 2018). Given the critical role of $\mathrm{Ca}^{2+}$ in angiogenesis, it is not surprising that $\beta$-TCP can effectively induce neovascularization. In a rabbit tibial defect model, significantly increased angiogenesis measured by average number of blood vessels, was observed in the $\beta$-TCP group $(4.47 \pm 0.2)$ compared with the bioactive glass group (1.58 \pm 0.246$)$ (Anghelescu et al., 2018). In clinical practice, similar results were observed when using $\beta$-TCPbased dental implants (Dautova et al., 2018). These results suggest $\beta$-TCP can augment angiogenesis, which could be the reason for its osteoinductivity (Kusumbe et al., 2014; Rather et al., 2019).

\section{The Incorporation of Bone Regenerative Growth Factors in Beta-Tricalcium Phosphate for Osteogenesis}

With a deeper understanding of bone repair and fracture union, studies have shown that the biological performance of scaffolds can be improved by incorporating certain growth factors (such as the BMP family). An in vitro study found that $\beta$-TCP particles exhibited excellent capacities to deliver growth factors from platelet concentrates such as BMP-2 and BMP-7, compared with the control group (non $\beta$-TCP particles) (Bonazza et al., 2018). Interestingly, in a rat femoral defect model, the residual $\beta$-TCP in the BMP-delivery treatment group was notably lower than the $\beta$-TCP control group, indicating that BMP may facilitate the degradation of $\beta$-TCP and subsequently enhance bone healing (Xie et al., 2019). Based on the aforementioned evidence, it is speculated that $\beta$-TCP could boost the process of bone regeneration via interacting with growth factors such as BMPs.

It has been demonstrated that growth factors play an important role in cell migration, cell proliferation, and tissue angiogenesis, further facilitating new bone formation at the defect 


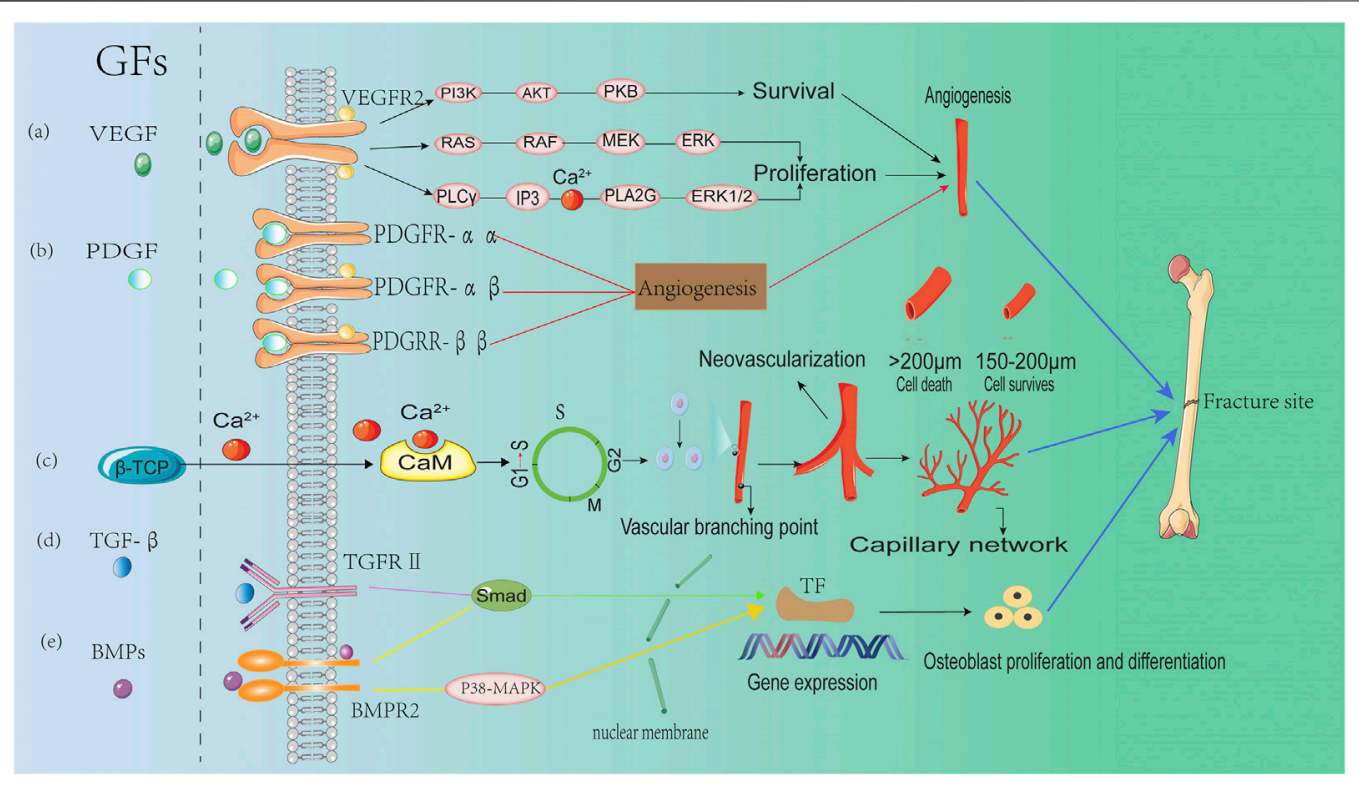

FIGURE 3 | The role of growth factors in regulating angiogenesis during bone formation (A) Vascular endothelial growth factor (VEGF) regulates osteogenesis through three major signaling pathways after binding to VEGFR2: the PI3K/AKT pathway, the Raf-MEK-ERK pathway and the PLC $\gamma$-IP3 pathway. (B) Platelet derived growth factor (PDGF) regulates angiogenesis by binding to and activating PDGFR- $\alpha \alpha$, PDGFR- $\alpha \beta$, and PDGFR- $\beta \beta$ receptors. (C) $\mathrm{Ca}^{2}$ released from $\beta$-TCP, binds to calmodulin $(\mathrm{CaM})$ to promote cell cycle progression $(\mathrm{G} 1 \rightarrow \mathrm{S})$, enhancing endothelial cell proliferation and facilitating neovascularization and bone healing. (D) Transforming growth factor beta (TGF- $\beta$ ) induces up-regulation of osteogenic gene expression through the SMAD signaling pathway after binding to transforming growth factor beta receptor2 (TGFR2). (E) Bone morphogenetic proteins (BMPs) facilitate the expression of osteogenic genes via bone morphogenetic protein receptor type-2 (BMPR) and the activation of SMAD and p38-MAPK signaling pathways.

sites (Kim et al., 2014; Mochizuki et al., 2020). Osteogenesis is the process by which new bone is synthesized by graft cells (mainly cells that survive on the surface of the graft) or host cells. During material-mediated osteoinduction, the migration and proliferation of undifferentiated host MSCs will be recruited to the defect sites, driven by growth factors such as BMPs, transforming growth factor beta (TGF- $\beta$ ) and platelet derived growth factor (PDGF). These growth factors have been found to induce early bone healing by binding to fibrinogen or extracellular matrix (ECM) proteins (Martino et al., 2013; Hulsart-Billstrom et al., 2015).

In a dog dehiscence defect model, $\beta$-TCP with fibroblast growth factor-2 (FGF-2) was demonstrated to increase bone volume compared with the $\beta$-TCP control (Fukuba et al., 2021). Similarly, the effect of FGF-2 on bone regeneration has been demonstrated in a canine maxillary saddle defect model (Hoshi et al., 2016). Furthermore, when $\beta$-TCP scaffolds containing $0.3 \%$ FGF-2 was implanted in patients with periodontal defects, the percentage of bone growth in the FGF-2- $\beta$-TCP treatment group was significantly increased compared with the $\beta$-TCP treatment group over a period of 13 months (Cochran et al., 2016). BMPs, members of the TGF- $\beta$ superfamily, can stimulate DNA recruitment and cell replication via SMAD and p38-MAPK signaling pathways, thereby promoting the directional differentiation of MSCs into osteoblasts. Accordingly, in an in vitro study, $\beta$-TCP granules were used to carry BMP-2, which led to a more pronounced osteogenic effect compared with the $\beta$-TCP control (Kuroiwa et al., 2019). Moreover, in a study using a rat calvarial bone defect model, BMP-2-loaded $\beta$-TCP granules significantly induced bone healing compared with the $\beta$-TCP group (Figure 3) (Lee et al., 2021).

\section{Modifying Beta-Tricalcium Phosphate in the Regulation of Blood Clots to Enhance Bone Regeneration}

The Effect of Blood Clots on Bone Healing

After implantation into the fracture site, the surface of substitute materials comes into contact with peripheral blood, which results in the formation of a blood clot around the graft (Milleret et al., 2015). In the case of a bone fracture, the blood clot acts as a 'natural scaffold' when the extrinsic coagulation pathway is activated (Einhorn and Gerstenfeld, 2015). Following a fracture, a cross-linked fibrin network is formed via the generation of thrombin, which strengthens clot formation by converting fibrinogen into fibrin. Coarse and loose fibrin clots have an increased rougher surface structure and a higher porosity which means it is more prone to undergo fibrinolysis, an enzymatic process by which fibrin is degraded and which has a beneficial process to the repair and regeneration of bone tissues (Yermolenko et al., 2011; Varin et al., 2013). Conversely, dense blood clots composed of thin and dense fibrin are highly resistant to fibrinolysis and result in a significant delay in bone regeneration (Wang et al., 2018b). As a consequence, the change in fibrin structure directly affects 


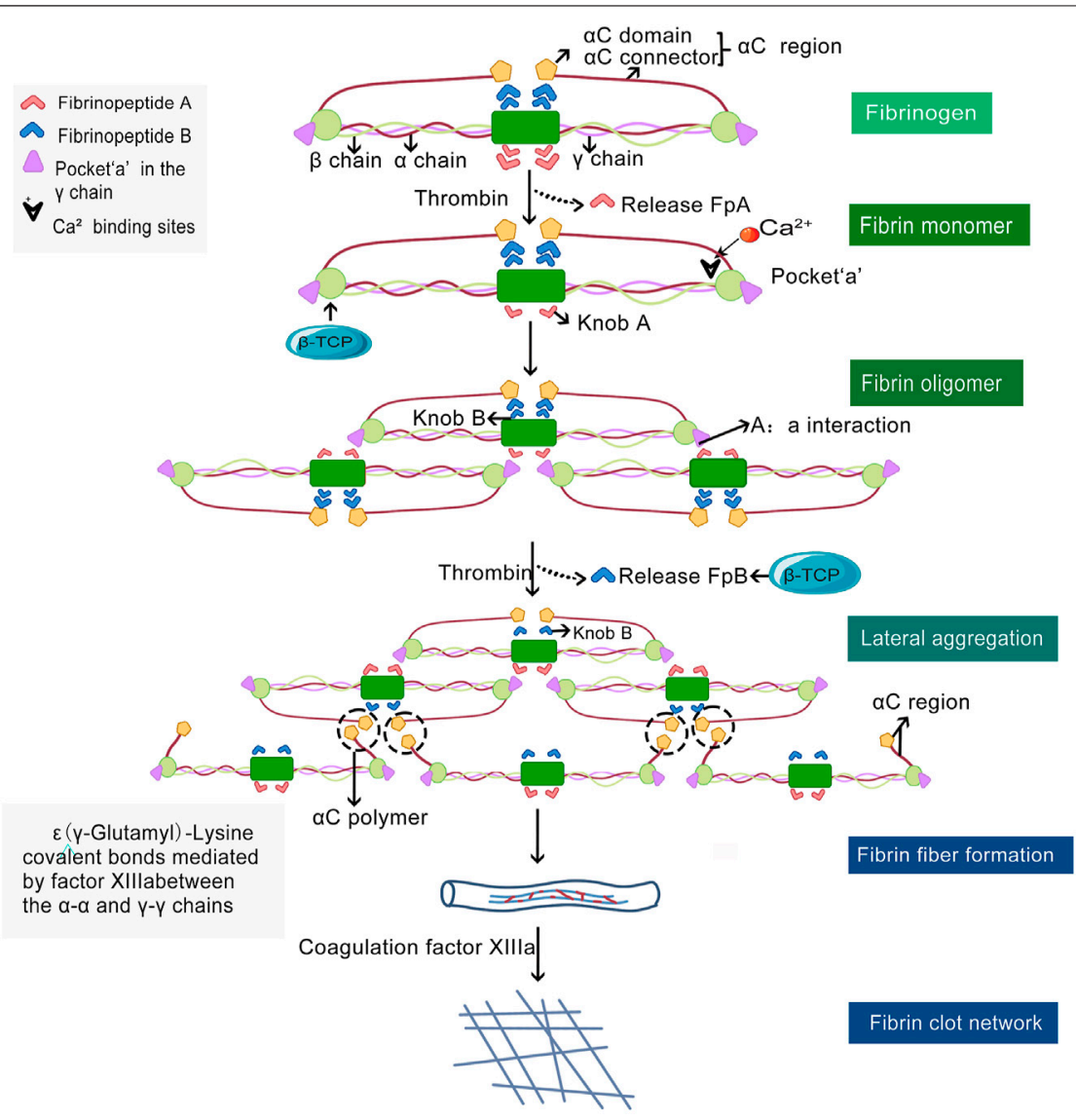

FIGURE 4 | Polymeric fibrin network formation and $\beta$-TCP regulatory sites. Thrombin mediates the of monomeric fibrinogen to polymeric fibrin by catalyzing the cleavage and release of fibrinopeptides (Fp)A (light red dovetail arrows) and FpB (blue dovetail arrows) from fibrinogen. Fibrin monomers originating from FpA aggregate longitudinally and form fibrin oligomers, which in turn polymerize to form protofibrils. The protofibrils undergo lateral polymerization via intermolecular interaction at $a \mathrm{C}$ regions to form $\mathrm{aC}$ polymers (black dashed circles) and results in the formation of thick fibers. Finally, the fibrin clot, a cross-linked gel-like meshwork forms and plays an important role in normal hemostasis. $\beta$-TCP may regulate fibrin polymerization at the cleavage sites when FpB is released and at the primary binding sites (black arrow heads) of the fibrinogen $\gamma$ chain (orange color).

the bone healing process, as fibrinolysis of the thrombus is responsible for cell growth and the release of growth factors (Laurens et al., 2006; Wang et al., 2016). Blood clots with a tight fibrin network delay bone healing due to the low porosity and delayed degradation (Wang et al., 2017b). On the contrary, thick fibrin blood clots with higher porosity facilitate osteoblast migration and adhesion, thereby promoting bone regeneration (Collen et al., 1998). Studies have demonstrated that the structure of blood clots at defects is closely related to thrombin concentration. Low concentrations of thrombin produce turbid, coarse and loose fibrin, leading to highly permeable fibrin clots. While high concentrations of thrombin result in non-turbid, thin and dense fibrin network chain and results in low permeability blood clots (Campbell et al., 2009; Rahmany et al., 2013).

Blood clots can also regulate bone regeneration via secreting growth factors. For example, platelet concentrate (PC) contains high levels of crucial growth factors for bone healing, including PDGF, TGF- $\beta$, insulin-like growth factor (IGF), epithelial growth factor (EGF) and VEGF (Qiao et al., 2017; Nagaraja et al., 2020;
Mijiritsky et al., 2021; Blatt et al., 2021). Moreover, PC also contains many soluble cytokines (CKs), such as proinflammatory response factors and anti-inflammatory response factors (Fang et al., 2020). These soluble CKs are important mediators of tissue healing process (Ma et al., 2019; Pennati et al., 2020). Studies have shown that PC can promote not only migration, proliferation, differentiation, and angiogenesis of adipose mesenchymal stem cells (ADSCs), but also ectopic osteogenesis (Chen et al., 2015b; Wang et al., 2015; Liou et al., 2018; Wang et al., 2019b; Ni et al., 2021).

\section{The Effect of Beta-Tricalcium Phosphate on Blood Clots}

Since blood clot formation is the first stage in the generation of new bone after material implantation, it is necessary to understand how $\beta$-TCP can regulate the formation and structure of new blood clots. Wang X et al. reported $\beta$-TCP solutions supplemented with increasing concentrations of fibrinogen resulted in a concomitant decrease in fibrin diameters (Wang et al., 2018a). Furthermore, the density of 
blood clots in the fibrinogen- $200 \mathrm{mg} / \mathrm{ml}$ group was markedly higher than the control group (Wang et al., 2018a) $\beta$-TCP is able to modulate the density of blood clots by regulating the formation of the fibrin network. This process involves the sequential cleavage of fibrin peptides (Fp)A and $\mathrm{FpB}$ from the central region of the fibrinogen molecule with subsequent longitudinal and lateral polymerization (Weisel and Litvinov, 2017). The fibrin monomers are gathered longitudinally through a knob-pocket interaction to form a fibrin oligomer, which then polymerizes to form fibrils (Weisel and Litvinov, 2013). Lateral polymerization occurs when fibrils form $\alpha \mathrm{C}$ polymers through intermolecular interactions mediated by activated factor XIII resulting in the formation of thick fibers. Together, longitudinal and lateral polymerization results in fibrin forming a crosslinked gel-like network (Weisel and Litvinov, 2013). During the process of fibrin polymerization, $\beta$-TCP may target this pathway by binding to the fibrinogen $\gamma$ chain of fibrinogen and result in the release of $\mathrm{FpB}$ (Figure 4).

\section{The Effect of $\mathrm{Ca}^{2+}$ on Blood Clots}

The release of $\mathrm{Ca}^{2+}$ from $\beta$-TCP plays a prominent role in the polymerization of fibrinogen. Fibrinogen contains both high and low $\mathrm{Ca}^{2+}$-binding sites; three high- and 8-10 low-affinity calcium binding sites (Weisel and Litvinov, 2017). Of the high-affinity $\mathrm{Ca}^{2+}$ binding sites in the $\gamma$ chains, $\gamma 1$, is associated with amino acid residues $\gamma$ Asp318, $\gamma$ Asp320, $\gamma$ Gly324, and $\gamma$ Phe322 and coordinated with two strongly bound water molecules (Spraggon et al., 1997; Kamijo et al., 2019). The remaining high-affinity $\mathrm{Ca}^{2+}$ binding sites (named $\beta 1$ ) are located at the $\beta$-nodules within loop $\beta 381-385$ and both have a coordinating water molecule (Everse et al., 1998). Of the low-affinity $\mathrm{Ca}^{2+}$ binding sites, $\gamma 2$ and $\beta 2$ have been well characterized. Formed as a consequence of molecular rearrangements as a result of crystal packing, $\gamma 2$ sites are located in loops $\gamma 294-301$ and exert only a moderate influence on the crystal structure and functional properties of fibrinogen (Kostelansky et al., 2004a; Kostelansky et al., 2004b; Kostelansky et al., 2007). The $\beta 2$ sites are formed by residues $\gamma$ Glu132, $\beta$ Asp261, $\beta$ Asp398, and the backbone carbonyl oxygen of $\gamma$ Glu132 (Kostelansky et al., 2004a; Kostelansky et al., $2004 \mathrm{~b})$. The $\beta$-nodules are anchored to the coiled-coil connector for functioning via $\beta 2$ sites, which are involved in the process of lateral aggregation of protofibrils (Kostelansky et al., 2004a).

The binding of $\mathrm{Ca}^{2+}$ to high-affinity sites protects the $\gamma$ chains from enzymatic degradation (Odrljin et al., 1996). and modulates fibrin polymerization by augmenting lateral aggregation to form thicker and denser fibers (Weisel and Litvinov, 2013). Consequently, functionality can be seriously damaged by mutations influencing these $\mathrm{Ca}^{2+}$ binding sites (Brennan et al., 2007). Furthermore, the conformational changes which occur when $\mathrm{FpB}$ is cleaved is $\mathrm{Ca}^{2+}$ dependent with the affinity of the $\mathrm{Ca}^{2+}$ binding sites changing upon FpB release (Dyr et al., 1989; Mihalyi 1988). The functional relevance of the $\beta 2$ site was elucidated when the binding of a knob ' $\mathrm{B}$ ' mimetic peptide (Gly His-Arg-Pro) in the presence of $\mathrm{Ca}^{2+}$ resulted in a 10 fold increased binding to fibrinogen compared with in the absence of $\mathrm{Ca}^{2+}$. This suggests the $\beta 2$ site may be involved in the conformational change associated with binding of Gly
His-Arg-Pro (Everse et al., 1999). The interval formed by dense fibers is inadequate to permit the entrance of osteogenic factors to the fracture site, resulting in delayed bone healing.

\section{$\mathrm{Ca}^{2+}$ Binding to Factor XIII Regulates the Crosslinking of Fibrin Monomers}

Under normal physiological conditions, $\mathrm{Ca}^{2+}$ is an essential factor involved in the extrinsic coagulation pathway (Figure 5). Plasma factor XIII, a $325.8 \mathrm{kDa}$ heterotetrameric proenzyme which stabilizes fibrin, is composed of two catalytic A subunits (FXIII-A) and two inhibitory B subunits (FXIII-B) (Ashcroft et al., 2000; Muszbek et al., 2011; Singh et al., 2019). It is the last factor in the coagulation cascade and facilitates crosslinking between fibrin monomers, protects fibrin from shear stress, and guards clots from premature degradation (Duval et al., 2014; Vasilyeva et al., 2018; Alshehri et al., 2021). For factor XIII to react with fibrin monomers, it is converted to an activated transglutaminase and functions in the presence of thrombin and $\mathrm{Ca}^{2+}$. The activation of plasma factor XIII under physiological conditions comprises two steps, firstly, the cleavage of a peptide from the N-terminal end of FXIII-A at Arg37-Gly38 by thrombin and secondly, the separation of FXIII-A from FXIII-B (in the presence of $\mathrm{Ca}^{2+}$ ) to form the active configuration. Thrombin can also inactivate FXIII-A by cleaving at Lys513-Ser514. $\mathrm{Ca}^{2+}$ is a key regulator of the proteolytic degradation of plasma factor XIII and can prevent thrombin-mediated inactivation of FXIII-A even at a very high concentrations of thrombin (Mary et al., 1988). After FXIII-A and FXIII-B subunits have been dissociated, $\mathrm{Ca}^{2+}$ binds to the high-affinity binding sites on FXIII-A to convert the free FXIII-A into an active transglutaminase, which subsequently facilitates the cross-linking and stabilization of fibrin monomers (Hornyak and Shafer, 1991; Hethershaw et al., 2014; Protopopova et al., 2019; Mangla et al., 2021). The formation of crosslinks, including $\alpha-\alpha, \quad \gamma-\gamma$, and $\alpha-\gamma$ crosslinking, have a variety of functions (Shainoff et al., 1991; Piechocka et al., 2017). The $\alpha-\alpha$ and to a certain extent, $\gamma-\gamma$ crosslinking play a vital role in regulating the physical properties of clots (e.g. stiffness, elasticity and tautness) compared with $\alpha-\gamma$ crosslinking (which affects the rigidity of clots less) (Duval et al., 2014; Standeven et al., 2007). In addition, the rate of crosslinking varies. For example, $\gamma-\gamma$ crosslinking is significantly quicker than $\alpha-\alpha$ crosslinking which is likely due to the complexity of $\alpha \mathrm{C}$ polymer formation (Guthold et al., 2007; Helms et al., 2012).

\section{The Effect of Polyphosphate lons on the Polymerization of Fibrin}

Inorganic polyphosphate (polyP) is a linear polymer composed of 60-100 orthophosphate residues linked by high-energy phosphoanhydride bonds (Muller et al., 2009; Ruiz et al., 2004). and functions to regulate the physical properties of fibrin clots and regulate fibrin polymerization (Whyte et al., 2016). It has been suggested that incorporation of the negatively charged polyP into fibrin is through the net positive charge on the $\mathrm{aC}$ regions of fibrinogen (Smith and Morrissey, 2008). This interaction increases the length of fibrin monomers, possibly as a result of the $\alpha \mathrm{C}$ region reaching beyond the D-region of the fibrin monomer. Furthermore, polyP may function to enhance 


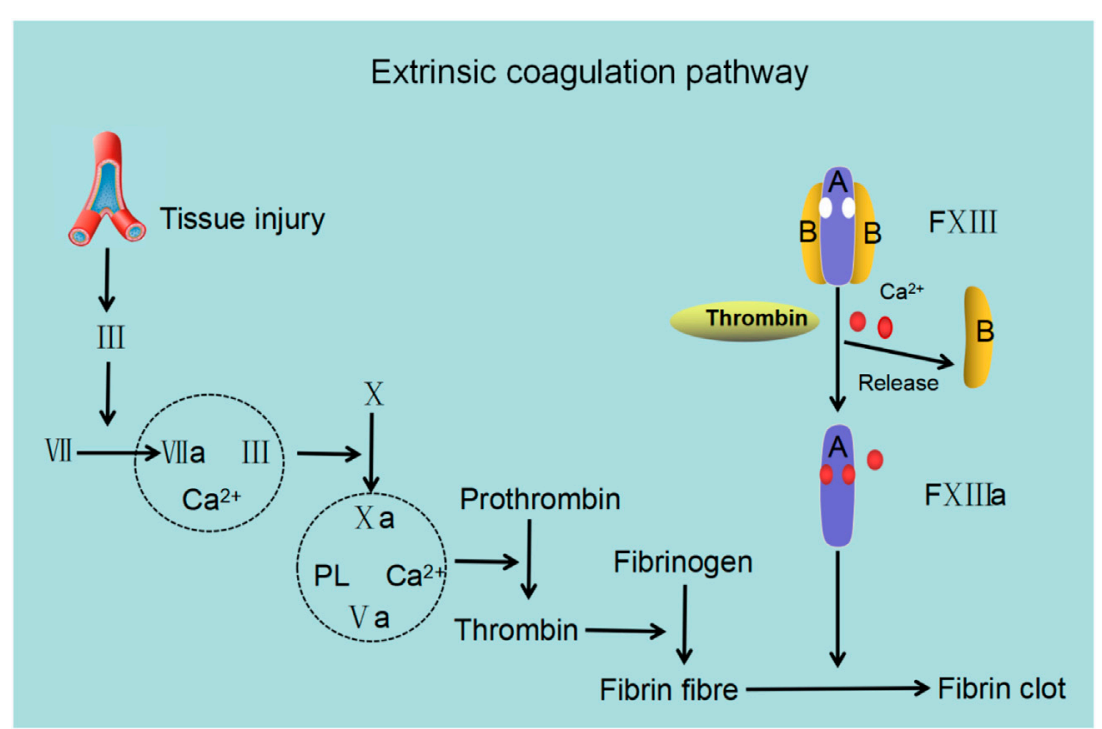

FIGURE 5 | The role of factor XIII in the extrinsic coagulation cascade. Following trauma, factor III (FIII; tissue factor) stimulates factor VII (FVII) to form an activated complex (TF-FVIla) wherein TF-FVlla activates factor X ( FX) to form FXa and converges into the common coagulation cascade. In the presence of $\mathrm{Ca}^{2+}$ and phospholipid

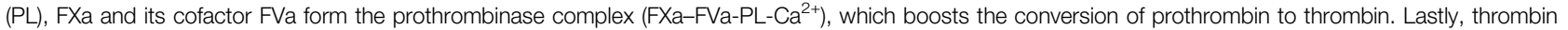
catalyzes fibrinogen to produce fibrin, leading to fibrin clot formation and achievement of hemostasis. Factor XIII (FXIII) contains two A subunits and two B subunits. The $\mathrm{B}$ subunit dissociates from the $\mathrm{A}$ subunit with the assistance of $\mathrm{Ca}^{2+}$ and thrombin and exposes $\mathrm{Ca}^{2+}$ binding sites resulting in the binding of $\mathrm{Ca}{ }^{2+}$ and $\mathrm{FXIII} \mathrm{facilitating}$ the stabilization and cross-linking of fibrin to form fibrin clots.

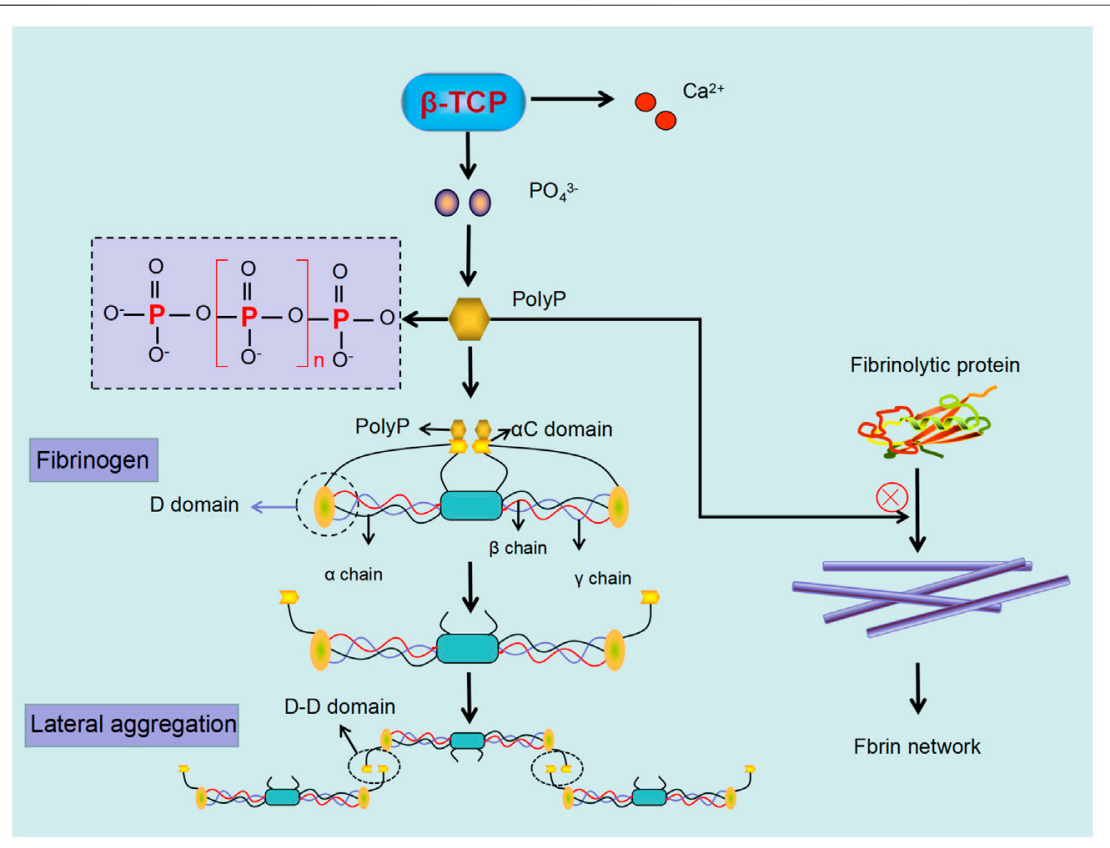

FIGURE 6 | Phosphate ions $\left(\mathrm{PO}_{4}{ }^{3-}\right)$ released from $\beta$-TCP can polymerize to form PolyP, which regulate fibrin polymerization and enhance resistance to fibrinolysis. PolyP binding to $\mathrm{a} C$ region in fibrinogen results in extension beyond the $\mathrm{D}$-region, with subsequent $\mathrm{D}$ - $\mathrm{D}$ interaction, resulting in lateral aggregation of fibrin. Moreover, the formed PolyP can further defend fibrinolytic protein from linking to the fibrin, leading to dense and undissolved fibrin.

D-D interactions between fibrin monomers as a result of lateral extension of aC region instead of longitudinal. This may account for shortened fibrin oligomers (Whyte et al., 2016). It is likely that polyP functions as a nucleus that attracts fibrinogen resulting in denser areas of fibrin (Whyte et al., 2016; Mutch 2016). Moreover, the presence of polyP can lead to more turbid fibrin clots and thicker fibrin fibrils compared with clots without polyp (Smith and Morrissey, 2014). PolyP 
seems to be directly integrated into fibrin clots, by currently an unknown mechanism.

In addition to altering the structure of the fibrin network, polyP also regulates fibrinolysis. The process of fibrinolysis, is regulated by tissue plasminogen activator (tPA) and urokinase (uPA). Both tPA and plasminogen exert their functions by attaching avidly to $\mathrm{C}$-terminal lysine residues on the fibrin surface (Foley et al., 2011). PolyP can inhibit fibrinolysis through modulating the binding of tPA and plasminogen to fibrin, although the detailed mechanism remains unclear (Morrissey and Smith, 2015; Mutch 2016). From the above considerations, we speculate that phosphate ions $\left(\mathrm{PO}_{4}{ }^{3-}\right)$ released from $\beta$-TCP form polyP which can lead to fibrin clots that are dense and more resistant to fibrinolysis. Moreover, as dense clots can hinder the migration of osteogenesis factors (Wang et al., 2016). and MSCs into the fracture site, polyP formation may be one of the possible mechanisms by which $\beta$-TCP delays bone regeneration (Figure 6).

\section{SUMMARY}

In this review, we have described recent advances in the application of $\beta$-TCP for bone regenerative medicine. $\beta$-TCP with its customizable pore size, porosity, and roughness, exhibits substantial advantages for the repair and regeneration of damaged bone tissues. Furthermore, the incorporation of other materials to modulate its hardness and ability to degrade can improve the mechanical performance of $\beta$-TCP. The porous structure of $\beta$-TCP can act as cargo carriers to deliver proosteogenic growth factors with favorable releasing kinetics and results in reduced side effects due to its inherent bioactivity. Compared to other biological materials, $\beta$-TCP has a more appropriate degradation rate, which is beneficial to the delivery of therapeutic ionic dissolution products.

Through the phenomenon $\beta$-TCP delays bone healing are observed just in several specific experimental models, the role of hematoma formation in osteogenesis is highlighted. The formation of a blood clot as a 'natural scaffold' is fundamental to early bone healing. Coarse and loose fibrin clots have a rougher surface structure, resulting in higher porosity and is more prone to undergo fibrinolysis. Consequently, this is favorable to the ingrowth of blood vessels and the adhesion of growth factors and MSCs, leading to successful bone regeneration. On the contrary, dense blood clots composed of thin and dense fibrin are highly

\section{REFERENCES}

Albrektsson, T., and Johansson, C. (2001). Osteoinduction, Osteoconduction and Osseointegration. Eur. Spine J. 10 (Suppl. 2), S96-S101. doi:10.1007/ s005860100282

Almansoori, A. A., Kwon, O. J., Nam, J. H., Seo, Y. K., Song, H. R., and Lee, J. H. (2021). Mesenchymal Stem Cells and Platelet-Rich Plasma-Impregnated Polycaprolactone- $\beta$ Tricalcium Phosphate Bio-Scaffold Enhanced Bone Regeneration Around Dental Implants. Int. J. Implant. Dent. 7, 35. doi:10.1186/s40729-021-00317-y resistant to fibrinolysis, resulting in a significant delay in the growth of new blood vessels, entry of growth factors and MSCs, leading to delayed bone regeneration. $\beta$-TCP, directly or indirectly (through its release of $\mathrm{Ca}^{2+}$ and $\mathrm{PO}_{4}{ }^{3-}$ ions), affect blood clot structure by regulating fibrin polymerization. The release of $\mathrm{Ca}^{2+}$ and subsequent binding to FXIII-A can accelerate fibrin polymerization and lead to fibrin that is highly resistant to fibrinolysis. The release of $\mathrm{PO}_{4}{ }^{3-}$ ions may initiate the formation of dense fibrin which is not susceptible to degradation. From this perspective, $\beta$-TCP may delay early bone regeneration and therefore further investigation is warranted to explore the effects of modified $\beta$-TCP materials on blood clot/ vessel formation to accelerate bone healing.

As yet, several methods have been discovered to control the structure of hematoma to facilitate bone regeneration, such as applying the copper $(\mathrm{Cu})$ dose gradient to realize the wellcontrolled nitric oxide (NO) releasing, which results in hematoma that is porous and susceptible to degradation. However, no perfect parameter or technique has been attained to endow a designable biomaterial with the desirable properties to completely control hematoma configuration. For this, more researches are required to gain knowledge of the key factors that have influence on the hematoma performance, thus finding suitable methods to manipulate hematoma formation to boost bone healing.

\section{AUTHOR CONTRIBUTIONS}

All authors listed have made a substantial, direct, and intellectual contribution to the work and approved it for publication.

\section{FUNDING}

This work was financially supported by the National Natural Science Foundation of China (Grant No. 86060620, 31960209, and 31760266), Guizhou Science and Technology Fund Project (Grant No. (2020)1Y093), the Scientific Innovation Foundation for Returned Overseas Chinese Scholars of Guizhou Province (Grant No. 2018-07), the 2018 Zunyi "15851 Talent Elite Project" (Grant No. National Natural Science Foundation of China 31760266), Doctoral Science Research Startup Funding of Zunyi Medical University (Grant No.F-934 and No.2017-01). Qian Wei Ji Ban Han (Grant No. 2017-24).
Alshehri, F. S. M., Whyte, C. S., and Mutch, N. J. (2021). Factor XIII-A: An Indispensable "Factor" in Haemostasis and Wound Healing. Int. J. Mol. Sci. 22, 3055. doi:10.3390/ijms22063055

Anghelescu, V. M., Neculae, I., Dinca, O., Vladan, C., Socoliuc, C., Cioplea, M., et al. (2018). Inflammatory-Driven Angiogenesis in Bone Augmentation with Bovine Hydroxyapatite, B-Tricalcium Phosphate, and Bioglasses: A Comparative Study. J. Immunol. Res. 2018, 9349207. doi:10.1155/2018/9349207

Ashcroft, A. E., Grant, P. J., and Ariens, R. A. (2000). A Study of Human Coagulation Factor XIII A-Subunit by Electrospray Ionisation Mass Spectrometry. Rapid Commun. Mass. Spectrom. 14, 1607-1611. doi:10.1002/ 1097-0231(20000915)14:17<1607::AID-RCM69>3.0.CO;2-L 
Babu, R. L., Naveen Kumar, M., Patil, R. H., Devaraju, K. S., Ramesh, G. T., and Sharma, S. C. (2013). Effect of Estrogen and Tamoxifen on the Expression Pattern of AP-1 Factors in MCF-7 Cells: Role of C-Jun, C-Fos, and Fra-1 in Cell Cycle Regulation. Mol. Cell. Biochem. 380, 143-151. doi:10.1007/s11010-0131667-x

Barbeck, M., Schröder, M. L., Alkildani, S., Jung, O., and Unger, R. E. (2021). Exploring the Biomaterial-Induced Secretome: Physical Bone Substitute Characteristics Influence the Cytokine Expression of Macrophages. Int. J. Mol. Sci. 22. doi:10.3390/ijms22094442

Barradas, A. M., Fernandes, H. A., Groen, N., Chai, Y. C., Schrooten, J., van de Peppel, J., et al. (2012). A Calcium-Induced Signaling cascade Leading to Osteogenic Differentiation of Human Bone Marrow-Derived Mesenchymal Stromal Cells. Biomaterials 33, 3205-3215. doi:10.1016/ j.biomaterials.2012.01.020

Bastami, F., Paknejad, Z., Jafari, M., Salehi, M., Rezai Rad, M., and Khojasteh, A. (2017). Fabrication of a Three-Dimensional $\beta$-tricalcium-phosphate/gelatin Containing Chitosan-Based Nanoparticles for Sustained Release of Bone Morphogenetic Protein-2: Implication for Bone Tissue Engineering. Mater. Sci. Eng. C. Mater. Biol. Appl. 72, 481-491. doi:10.1016/j.msec.2016.10.084

Blatt, S., Thiem, D. G. E., Pabst, A., Al-Nawas, B., and Kämmerer, P. W. (2021). Does Platelet-Rich Fibrin Enhance the Early Angiogenetic Potential of Different Bone Substitute Materials? An In Vitro and In Vivo Analysis. Biomedicines 9, 61. doi:10.3390/biomedicines 9010061

Blokhuis, T. J., Termaat, M. F., den Boer, F. C., Patka, P., Bakker, F. C., and Haarman, H. J. (2000). Properties of Calcium Phosphate Ceramics in Relation to Their In Vivo Behavior. J. Trauma 48, 179-186. doi:10.1097/00005373200001000-00037

Bonazza, V., Hajistilly, C., Patel, D., Patel, J., Woo, R., Cocchi, M. A., et al. (2018). Growth Factors Release from Concentrated Growth Factors: Effect of BetaTricalcium Phosphate Addition. J. Craniofac. Surg. 29, 2291-2295. doi:10.1097/ SCS.0000000000004607

Brennan, S. O., Davis, R. L., Mosesson, M. W., Hernandez, I., Lowen, R., and Alexander, S. J. (2007). Congenital Hypodysfibrinogenaemia (Fibrinogen Des Moines) Due to a gamma320Asp Deletion at the Ca2+ Binding Site. Thromb. Haemost. 98, 467-469. doi:10.1160/th07-05-0354

Campbell, R. A., Overmyer, K. A., Selzman, C. H., Sheridan, B. C., and Wolberg, A. S. (2009). Contributions of Extravascular and Intravascular Cells to Fibrin Network Formation, Structure, and Stability. Blood 114, 4886-4896. doi:10.1182/blood-2009-06-228940

Canullo, L., Tronchi, M., Kawakami, S., Iida, T., Signorini, L., and Mordini, L. (2019). Horizontal Bone Augmentation in the Anterior Esthetic Area of the Maxilla Using a Flap Design Adapted from Mucogingival Surgery in Association with PLA Membrane and Beta-TCP. Int. J. Periodontics Restorative Dent. 39, 195-201. doi:10.11607/prd.3894

Cao, L., Chen, Q., Jiang, L. B., Yin, X. F., Bian, C., Wang, H. R., et al. (2017). Bioabsorbable Self-Retaining PLA/nano-sized Beta-TCP Cervical Spine Interbody Fusion Cage in Goat Models: an In Vivo Study. Int. J. Nanomedicine 12, 7197-7205. doi:10.2147/IJN.S132041

Cao, Q., He, Z., Sun, W. Q., Fan, G., Zhao, J., Bao, N., et al. (2019). Improvement of Calcium Phosphate Scaffold Osteogenesis In Vitro via Combination of Glutamate-Modified BMP-2 Peptides. Mater. Sci. Eng. C, Mater. Biol. Appl. 96, 412-418. doi:10.1016/j.msec.2018.11.048

Cary, R. L., Waddell, S., Racioppi, L., Long, F., Novack, D. V., Voor, M. J., et al. (2013). Inhibition of $\mathrm{Ca}^{2+} /$ calmodulin-dependent Protein Kinase Kinase 2 Stimulates Osteoblast Formation and Inhibits Osteoclast Differentiation. J. Bone Mineral Res. 28, 1599-1610. doi:10.1002/jbmr.1890

Chen, Y. L., Sun, C. K., Tsai, T. H., Chang, L. T., Leu, S., Zhen, Y. Y., et al. (2015b). Adipose-derived Mesenchymal Stem Cells Embedded in Platelet-Rich Fibrin Scaffolds Promote Angiogenesis, Preserve Heart Function, and Reduce Left Ventricular Remodeling in Rat Acute Myocardial Infarction. Am. J. translational Res. 7, 781-803.

Chen, Z., Yuen, J., Crawford, R., Chang, J., Wu, C., and Xiao, Y. (2015a). The Effect of Osteoimmunomodulation on the Osteogenic Effects of Cobalt Incorporated Beta-Tricalcium Phosphate. Biomaterials 61, 126-138. doi:10.1016/ j.biomaterials.2015.04.044

Cheng, L., Lin, T., Khalaf, A. T., Zhang, Y., He, H., Yang, L., et al. (2021). The Preparation and Application of Calcium Phosphate Biomedical Composites in
Filling of Weight-Bearing Bone Defects. Sci. Rep. 11, 4283. doi:10.1038/s41598021-83941-3

Choo, T., Marino, V., and Bartold, P. M. (2013). Effect of PDGF-BB and BetaTricalcium Phosphate (Beta-TCP) on Bone Formation Around Dental Implants: a Pilot Study in Sheep. Clin. Oral Implants Res. 24, 158-166. doi:10.1111/j.1600-0501.2011.02345.x

Choy, C., Lee, W., Lin, P., Wu, Y., Huang, H., Teng, N., et al. (2021). Surface Modified $\beta$-Tricalcium Phosphate Enhanced Stem Cell Osteogenic Differentiation In Vitro and Bone Regeneration In Vivo. Scientific Rep. 11, 9234. doi:10.1038/s41598-021-88402-5

Chu, W., Wang, X., Gan, Y., Zhuang, Y., Shi, D., Liu, F., et al. (2019). Screen-enrichcombine Circulating System to Prepare MSC/ $\beta$-TCP for Bone Repair in Fractures with Depressed Tibial Plateau. Regenerative Med. 14, 555-569. doi:10.2217/rme-2018-0047

Cochran, D. L., Oh, T. J., Mills, M. P., Clem, D. S., McClain, P. K., Schallhorn, R. A., et al. (2016). A Randomized Clinical Trial Evaluating Rh-FGF-2/ beta-TCP in Periodontal Defects. J. Dent. Res. 95, 523-530. doi:10.1177/ 0022034516632497

Collen, A., Koolwijk, P., Kroon, M., and van Hinsbergh, V. W. (1998). Influence of Fibrin Structure on the Formation and Maintenance of Capillary-like Tubules by Human Microvascular Endothelial Cells. Angiogenesis 2, 153-165. doi:10.1023/a:1009240522808

Dantas, T. A., Abreu, C. S., Costa, M. M., Miranda, G., Silva, F. S., Dourado, N., et al. (2017). Bioactive Materials Driven Primary Stability on Titanium Biocomposites. Mater. Sci. Eng. C, Mater. Biol. Appl. 77, 1104-1110. doi:10.1016/j.msec.2017.04.014

Dautova, Y., Kapustin, A. N., Pappert, K., Epple, M., Okkenhaug, H., Cook, S. J., et al. (2018). Calcium Phosphate Particles Stimulate Interleukin-1beta Release from Human Vascular Smooth Muscle Cells: A Role for Spleen Tyrosine Kinase and Exosome Release. J. Mol. Cel Cardiol. 115, 82-93. doi:10.1016/ j.yjmcc.2017.12.007

Davison, N. L., Luo, X., Schoenmaker, T., Everts, V., Yuan, H., Barrère-de Groot, F., et al. (2014). Submicron-scale Surface Architecture of Tricalcium Phosphate Directs Osteogenesis In Vitro and In Vivo. Eur. Cell Mater. 27, 281-297. doi:10.22203/ecm.v027a20

Dong, S., Zhang, Y. N., Wan, J., Cui, R., Yu, X., Zhao, G., et al. (2020). A Novel Multifunctional Carbon Aerogel-Coated Platform for Osteosarcoma Therapy and Enhanced Bone Regeneration. J. Mater. Chem. B. 8, 368-379. doi:10.1039/ c9tb02383f

Dos Santos Trento, G., Hassumi, J. S., Buzo Frigério, P., Farnezi Bassi, A. P., Okamoto, R., Gabrielli, M. A. C., et al. (2020). Gene Expression, Immunohistochemical and Microarchitectural Evaluation of Bone Formation Around Two Implant Surfaces Placed in Bone Defects Filled or Not with Bone Substitute Material. Int. J. Implant Dent. 6, 80. doi:10.1186/ s40729-020-00279-7

Du, F., Wang, Q., Ouyang, L., Wu, H., Yang, Z., Fu, X., et al. (2021). Comparison of Concentrated Fresh Mononuclear Cells and Cultured Mesenchymal Stem Cells from Bone Marrow for Bone Regeneration. Stem Cell Transl. Med. 10, 598-609. doi:10.1002/sctm.20-0234

Duval, C., Allan, P., Connell, S. D., Ridger, V. C., Philippou, H., and Ariëns, R. A. (2014). Roles of Fibrin $\alpha$ - and $\gamma$-chain Specific Cross-Linking by FXIIIa in Fibrin Structure and Function. Thromb. Haemost. 111, 842-850. doi:10.1160/ th13-10-0855

Dyr, J. E., Blomback, B., Hessel, B., and Kornalik, F. (1989). Conversion of Fibrinogen to Fibrin Induced by Preferential Release of Fibrinopeptide B. Biochim. Biophys. Acta 990, 18-24. doi:10.1016/s0304-4165(89)80006-6

Einhorn, T. A., and Gerstenfeld, L. C. (2015). Fracture Healing: Mechanisms and Interventions. Nat. Rev. Rheumatol. 11, 45-54. doi:10.1038/ nrrheum.2014.164

Enderle, R., Götz-Neunhoeffer, F., Göbbels, M., Müller, F. A., and Greil, P. (2005). Influence of Magnesium Doping on the Phase Transformation Temperature of Beta-TCP Ceramics Examined by Rietveld Refinement. Biomaterials 26, 3379-3384. doi:10.1016/j.biomaterials.2004.09.017

Everse, S. J., Spraggon, G., Veerapandian, L., and Doolittle, R. F. (1999). Conformational Changes in Fragments $\mathrm{D}$ and Double-D from Human Fibrin(ogen) upon Binding the Peptide Ligand Gly-His-Arg-Pro-Amide. Biochemistry 38, 2941-2946. doi:10.1021/bi982626w 
Everse, S. J., Spraggon, G., Veerapandian, L., Riley, M., and Doolittle, R. F. (1998). Crystal Structure of Fragment Double-D from Human Fibrin with Two Different Bound Ligands. Biochemistry 37, 8637-8642. doi:10.1021/bi9804129

Faia-Torres, A. B., Charnley, M., Goren, T., Guimond-Lischer, S., Rottmar, M., Maniura-Weber, K., et al. (2015). Osteogenic Differentiation of Human Mesenchymal Stem Cells in the Absence of Osteogenic Supplements: A Surface-Roughness Gradient Study. Acta Biomater. 28, 64-75. doi:10.1016/ j.actbio.2015.09.028

Fang, J., Wang, X., Jiang, W., Zhu, Y., Hu, Y., Zhao, Y., et al. (2020). Platelet-Rich Plasma Therapy in the Treatment of Diseases Associated with Orthopedic Injuries. Tissue Engineering. Part. B, Rev. 26, 571-585. doi:10.1089/ ten.TEB.2019.0292

Fielding, G. A., Sarkar, N., Vahabzadeh, S., and Bose, S. (2019). Regulation of Osteogenic Markers at Late Stage of Osteoblast Differentiation in Silicon and Zinc Doped Porous TCP. J. Funct. Biomater. 10, 48. doi:10.3390/jfb10040048

Foley, J. H., Cook, P. F., and Nesheim, M. E. (2011). Kinetics of Activated Thrombin-Activatable Fibrinolysis Inhibitor (TAFIa)-Catalyzed Cleavage of C-Terminal Lysine Residues of Fibrin Degradation Products and Removal of Plasminogen-Binding Sites. J. Biol. Chem. 286, 19280-19286. doi:10.1074/ jbc.M110.215061

Fukuba, S., Akizuki, T., Matsuura, T., Okada, M., Nohara, K., Hoshi, S., et al. (2021). Effects of Combined Use of Recombinant Human Fibroblast Growth Factor- 2 and $\beta$-tricalcium Phosphate on ridge Preservation in Dehiscence Bone Defects after Tooth Extraction: A Split-Mouth Study in Dogs. J. Periodontal Res. 56, 298-305. doi:10.1111/jre.12818

Gilev, M. V., Bazarny, V. V., Volokitina, E. A., Polushina, L. G., Maksimova, A. Y., and Kazakova, Y. E. (2019). Laboratory Monitoring of Bone Tissue Remodeling after Augmentation of Impression Intraarticular Fracture with Different Types of Bone Graft. Bull. Exp. Biol. Med. 167, 681-684. doi:10.1007/s10517-01904598-7

Gu, Y., Zhang, J., Zhang, X., Liang, G., Xu, T., and Niu, W. (2019). Threedimensional Printed Mg-Doped $\beta$-TCP Bone Tissue Engineering Scaffolds: Effects of Magnesium Ion Concentration on Osteogenesis and Angiogenesis In Vitro. Tissue Eng. Regenerative Med. 16, 415-429. doi:10.1007/s13770-01900192-0

Guthold, M., Liu, W., Sparks, E. A., Jawerth, L. M., Peng, L., Falvo, M., et al. (2007). A Comparison of the Mechanical and Structural Properties of Fibrin Fibers with Other Protein Fibers. Cell Biochem. Biophys. 49, 165-181. doi:10.1007/s12013007-9001-4

Han, X., Gao, Y., Ding, Y., Wang, W., Liu, L., Zhao, A., et al. (2021). In Vitro performance of 3D Printed PCL- $\beta$-TCP Degradable Spinal Fusion Cage. J. Biomater. Appl. 35, 1304-1314. doi:10.1177/0885328220978492

Hannink, G., and Arts, J. J. (2011). Bioresorbability, Porosity and Mechanical Strength of Bone Substitutes: what Is Optimal for Bone Regeneration? Injury 42 (Suppl. 2), S22-S25. doi:10.1016/j.injury.2011.06.008

Helms, C. C., Ariëns, R. A., Uitte de Willige, S., Standeven, K. F., and Guthold, M. (2012). $\alpha$ - $\alpha$ Cross-Links Increase Fibrin Fiber Elasticity and Stiffness. Biophys. J. 102, 168-175. doi:10.1016/j.bpj.2011.11.4016

Hethershaw, E. L., Cilia La Corte, A. L., Duval, C., Ali, M., Grant, P. J., Ariëns, R. A., et al. (2014). The Effect of Blood Coagulation Factor XIII on Fibrin Clot Structure and Fibrinolysis. J. Thromb. Haemost. 12, 197-205. doi:10.1111/ jth. 12455

Hornyak, T. J., and Shafer, J. A. (1991). Role of Calcium Ion in the Generation of Factor XIII Activity. Biochemistry 30, 6175-6182. doi:10.1021/bi00239a014

Hoshi, S., Akizuki, T., Matsuura, T., Ikawa, T., Kinoshita, A., Oda, S., et al. (2016). Ridge Augmentation Using Recombinant Human Fibroblast Growth Factor-2 with Biodegradable Gelatin Sponges Incorporating BetaTricalcium Phosphate: a Preclinical Study in Dogs. J. Periodontal Res. 51, 77-85. doi:10.1111/jre.12285

Hui, S., Choi, J., Zaidi, S., Momen, A., Steinbach, S. K., Sadi, A. M., et al. (2011). Peptide-mediated Disruption of Calmodulin-Cyclin E Interactions Inhibits Proliferation of Vascular Smooth Muscle Cells and Neointima Formation. Circ. Res. 108, 1053-1062. doi:10.1161/circresaha.110.239483

Hulsart-Billstrom, G., Bergman, K., Andersson, B., Hilborn, J., Larsson, S., and Jonsson, K. B. (2015). A Uni-Cortical Femoral Defect Model in the Rat: Evaluation Using Injectable Hyaluronan Hydrogel as a Carrier for Bone Morphogenetic Protein-2. J. Tissue Eng. Regen. Med. 9, 799-807. doi:10.1002/term.1655
Imanishi, Y., Hata, M., Matsukawa, R., Aoyagi, A., Omi, M., Mizutani, M., et al. (2021). Efficacy of Extracellular Vesicles from Dental Pulp Stem Cells for Bone Regeneration in Rat Calvarial Bone Defects. Inflamm. Regen. 41, 12. doi:10.1186/s41232-021-00163-w

Ishikawa, K., Putri, T. S., Tsuchiya, A., Tanaka, K., and Tsuru, K. (2018). Fabrication of Interconnected Porous $\beta$-tricalcium Phosphate ( $\beta$-TCP) Based on a Setting Reaction of $\beta$-TCP Granules with HNO(3) Followed by Heat Treatment. J. Biomed. Mater. Res. A. 106, 797-804. doi:10.1002/ jbm.a.36285

Ji, H., Huang, Z., Xia, Z., Molokeev, M. S., Atuchin, V. V., and Huang, S. (2014). Cation Substitution Dependent Bimodal Photoluminescence in Whitlockite Structural $\mathrm{Ca}(3-\mathrm{x}) \mathrm{Sr}(\mathrm{x})(\mathrm{PO} 4) 2 \mathrm{Eu}(2+)(0 \leq \mathrm{X} \leq 2)$ Solid Solution Phosphors. Inorg. Chem. 53, 11119-11124. doi:10.1021/ic501679f

Jin, Y., Muhl, L., Burmakin, M., Wang, Y., Duchez, A. C., Betsholtz, C., et al. (2017). Endoglin Prevents Vascular Malformation by Regulating Flow-Induced Cell Migration and Specification through VEGFR2 Signalling. Nat. Cel. Biol. 19, 639-652. doi:10.1038/ncb3534

Kahl, C. R., and Means, A. R. (2003). Regulation of Cell Cycle Progression by Calcium/calmodulin-dependent Pathways. Endocr. Rev. 24, 719-736. doi:10.1210/er.2003-0008

Kamijo, T., Mukai, S., Taira, C., Higuchi, Y., and Okumura, N. (2019). $\gamma$ D318Y Fibrinogen Shows No Fibrin Polymerization Due to Defective "A-A" and "B-B" Interactions, whereas that of $\gamma \mathrm{K} 321 \mathrm{E}$ Fibrinogen Is Nearly normal. Thromb. Res. 182, 150-158. doi:10.1016/j.thromres.2019.08.017

Kang, H.-J., Makkar, P., Padalhin, A. R., Lee, G.-H., Im, S.-B., and Lee, B.-T. (2020). Comparative Study on Biodegradation and Biocompatibility of Multichannel Calcium Phosphate Based Bone Substitutes. Mater. Sci. Eng. C 110, 110694. doi:10.1016/j.msec.2020.110694

Karageorgiou, V., and Kaplan, D. (2005). Porosity of 3D Biomaterial Scaffolds and Osteogenesis. Biomaterials 26, 5474-5491. doi:10.1016/ j.biomaterials.2005.02.002

Kim, B. S., Yang, S. S., You, H. K., Shin, H. I., and Lee, J. (2018). Fucoidan-induced Osteogenic Differentiation Promotes Angiogenesis by Inducing Vascular Endothelial Growth Factor Secretion and Accelerates Bone Repair. J. Tissue Eng. Regen. Med. 12, e1311-e1324. doi:10.1002/term.2509

Kim, T. H., Kim, S. H., Sandor, G. K., and Kim, Y. D. (2014). Comparison of Platelet-Rich Plasma (PRP), Platelet-Rich Fibrin (PRF), and Concentrated Growth Factor (CGF) in Rabbit-Skull Defect Healing. Arch. Oral Biol. 59, 550-558. doi:10.1016/j.archoralbio.2014.02.004

Kim, W., and Kim, G. (2019). Collagen/bioceramic-based Composite Bioink to Fabricate a Porous 3D hASCs-Laden Structure for Bone Tissue Regeneration. Biofabrication 12, 015007. doi:10.1088/1758-5090/ab436d

Kostelansky, M. S., Bolliger-Stucki, B., Betts, L., Gorkun, O. V., and Lord, S. T. (2004b). B Beta Glu397 and B Beta Asp398 but Not B Beta Asp432 Are Required for "B:b" Interactions. Biochemistry 43, 2465-2474. doi:10.1021/bi035996f

Kostelansky, M. S., Lounes, K. C., Ping, L. F., Dickerson, S. K., Gorkun, O. V., and Lord, S. T. (2004a). Calcium-binding Site Beta 2, Adjacent to the "b" Polymerization Site, Modulates Lateral Aggregation of Protofibrils during Fibrin Polymerization. Biochemistry 43, 2475-2483. doi:10.1021/bi0359978

Kostelansky, M. S., Lounes, K. C., Ping, L. F., Dickerson, S. K., Gorkun, O. V., and Lord, S. T. (2007). Probing the Gamma2 Calcium-Binding Site: Studies with gammaD298,301A Fibrinogen Reveal Changes in the Gamma294-301 Loop that Alter the Integrity of the "a" Polymerization Site. Biochemistry 46, 5114-5123. doi:10.1021/bi602607a

Koval, O. M., Nguyen, E. K., Santhana, V., Fidler, T. P., Sebag, S. C., Rasmussen, T. P., et al. (2019). Loss of MCU Prevents Mitochondrial Fusion in G(1)-S Phase and Blocks Cell Cycle Progression and Proliferation. Sci. Signal. 12, eaav1439. doi:10.1126/scisignal.aav1439

Kowalczyk, P., Podgórski, R., Wojasiński, M., Gut, G., Bojar, W., and Ciach, T. (2021). Chitosan-Human Bone Composite Granulates for Guided Bone Regeneration. Int. J. Mol. Sci. 22, 2324. doi:10.3390/ijms22052324

Krock, B. L., Skuli, N., and Simon, M. C. (2011). Hypoxia-induced Angiogenesis: Good and Evil. Genes Cancer 2, 1117-1133. doi:10.1177/1947601911423654

Kukushkin, A. N., Abramova, M. V., Svetlikova, S. B., Darieva, Z. A., Pospelova, T. V., and Pospelov, V. A. (2002). Downregulation of C-Fos Gene Transcription in Cells Transformed by E1A and cHa-Ras Oncogenes: a Role of Sustained Activation of MAP/ERK Kinase cascade and of Inactive Chromatin 
Structure at C-Fos Promoter. Oncogene 21, 719-730. doi:10.1038/ sj.onc. 1205118

Kuroiwa, Y., Niikura, T., Lee, S. Y., Oe, K., Iwakura, T., Fukui, T., et al. (2019). Escherichia Coli-Derived BMP-2-Absorbed Beta-TCP Granules Induce Bone Regeneration in Rabbit Critical-Sized Femoral Segmental Defects. Int. Orthop. 43, 1247-1253. doi:10.1007/s00264-018-4079-4

Kusumbe, A. P., Ramasamy, S. K., and Adams, R. H. (2014). Coupling of Angiogenesis and Osteogenesis by a Specific Vessel Subtype in Bone. Nature 507, 323-328. doi:10.1038/nature13145

Laurens, N., Koolwijk, P., and de Maat, M. P. (2006). Fibrin Structure and Wound Healing. J. Thromb. Haemost. 4, 932-939. doi:10.1111/j.1538-7836.2006.01861.x

Lee, D. K., Ki, M. R., Kim, E. H., Park, C. J., Ryu, J. J., Jang, H. S., et al. (2021). Biosilicated Collagen $/ \beta$-Tricalcium Phosphate Composites as a BMP-2Delivering Bone-Graft Substitute for Accelerated Craniofacial Bone Regeneration. Biomater. Res. 25, 13. doi:10.1186/s40824-021-00214-w

Lee, S., Choi, D., Shim, J. H., and Nam, W. (2020). Efficacy of Three-Dimensionally Printed Polycaprolactone/beta Tricalcium Phosphate Scaffold on Mandibular Reconstruction. Sci. Rep. 10, 4979. doi:10.1038/s41598-020-61944-w

Lei, Q., Lin, D., Huang, W. X., Wu, D., and Chen, J. (2018). Effects of Calcium Ion on the Migration and Osteogenic Differentiation of Human Osteoblasts. Hua Xi Kou Qiang Yi Xue Za Zhi 36, 602-608. doi:10.7518/hxkq.2018.06.004

Li, X. X., Liu, Y. M., Li, Y. J., Xie, N., Yan, Y. F., Chi, Y. L., et al. (2016). High Glucose Concentration Induces Endothelial Cell Proliferation by Regulating Cyclin-D2Related miR-98. J. Cell. Mol. Med. 20, 1159-1169. doi:10.1111/jcmm.12765

Lim, H. K., Hong, S. J., Byeon, S. J., Chung, S. M., On, S. W., Yang, B. E., et al. (2020). 3D-Printed Ceramic Bone Scaffolds with Variable Pore Architectures. Int. J. Mol. Sci. 21, 6942. doi:10.3390/ijms21186942

Liou, J. J., Rothrauff, B. B., Alexander, P. G., and Tuan, R. S. (2018). Effect of Platelet-Rich Plasma on Chondrogenic Differentiation of Adipose- and Bone Marrow-Derived Mesenchymal Stem Cells. Tissue Eng. Part. A. 24, 1432-1443. doi:10.1089/ten.tea.2018.0065

Liu, J., Zhou, P., Smith, J., Xu, S., and Huang, C. (2021). A Plastic $\beta$-Tricalcium Phosphate/Gelatine Scaffold Seeded with Allogeneic Adipose-Derived Stem Cells for Mending Rabbit Bone Defects. Cell Reprogram. 23, 35-46. doi:10.1089/ cell.2020.0031

Liu, W., Le, C. C., Wang, D., Ran, D., Wang, Y., Zhao, H., et al. (2020). Ca(2+)/ $\mathrm{CaM} / \mathrm{CaMK}$ Signaling Is Involved in Cadmium-Induced Osteoclast Differentiation. Toxicology 441, 152520. doi:10.1016/j.tox.2020.152520

Liu, Y., Chan, J. K., and Teoh, S. H. (2015). Review of Vascularised Bone TissueEngineering Strategies with a Focus on Co-culture Systems. J. Tissue Eng. Regen. Med. 9, 85-105. doi:10.1002/term.1617

Loh, Q. L., and Choong, C. (2013). Three-dimensional Scaffolds for Tissue Engineering Applications: Role of Porosity and Pore Size. Tissue Eng. Part. B, Rev. 19, 485-502. doi:10.1089/ten.TEB.2012.0437

Lopez-Heredia, M. A., Sariibrahimoglu, K., Yang, W., Bohner, M., Yamashita, D., Kunstar, A., et al. (2012). Influence of the Pore Generator on the Evolution of the Mechanical Properties and the Porosity and Interconnectivity of a Calcium Phosphate Cement. Acta Biomater. 8, 404-414. doi:10.1016/ j.actbio.2011.08.010

Lu, D. Z., Dong, W., Feng, X. J., Chen, H., Liu, J. J., Wang, H., et al. (2020b). CaMKII $(\delta)$ Regulates Osteoclastogenesis through ERK, JNK, and P38 MAPKs and CREB Signalling Pathway. Mol. Cell. Endocrinol. 508, 110791. doi:10.1016/ j.mce.2020.110791

Lu, T., Feng, S., He, F., and Ye, J. (2020a). Enhanced Osteogenesis of Honeycomb $\beta$-tricalcium Phosphate Scaffold by Construction of Interconnected Pore Structure: An In vivo Study. J. Biomed. Mater. Res. Part A. 108, 645-653. doi:10.1002/jbm.a.36844

Ma, Y., Zhou, Y., Wu, F., Ji, W., Zhang, J., and Wang, X. (2019). The Bidirectional Interactions Between Inflammation and Coagulation in Fracture Hematoma. Tissue Eng. B, Rev. 25, 46-54. doi:10.1089/ten.TEB.2018.0157

Ma, Z. P., Liao, J. C., Zhao, C., and Cai, D. Z. (2015). Effects of the 1, 4dihydropyridine L-type Calcium Channel Blocker Benidipine on Bone Marrow Stromal Cells. Cel Tissue Res. 361, 467-476. doi:10.1007/s00441015-2115-X

Maeno, S., Niki, Y., Matsumoto, H., Morioka, H., Yatabe, T., Funayama, A., et al. (2005). The Effect of Calcium Ion Concentration on Osteoblast Viability, Proliferation and Differentiation in Monolayer and 3D Culture. Biomaterials 26, 4847-4855. doi:10.1016/j.biomaterials.2005.01.006
Majidinia, M., Sadeghpour, A., and Yousefi, B. (2018). The Roles of Signaling Pathways in Bone Repair and Regeneration. J. Cell. Physiol. 233, 2937-2948. doi: $10.1002 /$ jcp. 26042

Mangla, A., Hamad, H., and Kumar, A. (2021). "Factor XIII Deficiency," in StatPearls (Treasure Island (FL): StatPearls Publishing LLC). Copyright $\odot 2021$.

Martineau, X., Abed, É., Martel-Pelletier, J., Pelletier, J. P., and Lajeunesse, D. (2017). Alteration of Wnt5a Expression and of the Non-canonical Wnt/PCP and Wnt/PKC-Ca2+ Pathways in Human Osteoarthritis Osteoblasts. PloS One 12, e0180711. doi:10.1371/journal.pone.0180711

Martino, M. M., Briquez, P. S., Ranga, A., Lutolf, M. P., and Hubbell, J. A. (2013). Heparin-binding Domain of Fibrin(ogen) Binds Growth Factors and Promotes Tissue Repair when Incorporated within a Synthetic Matrix. Proc. Natl. Acad. Sci. U S A. 110, 4563-4568. doi:10.1073/pnas.1221602110

Mary, A., Achyuthan, K. E., and Greenberg, C. S. (1988). B-Chains Prevent the Proteolytic Inactivation of the A-Chains of Plasma Factor XIII. Biochim. Biophys. Acta 966, 328-335. doi:10.1016/0304-4165(88)90082-7

Masaoka, T., Yoshii, T., Yuasa, M., Yamada, T., Taniyama, T., Torigoe, I., et al. (2016). Bone Defect Regeneration by a Combination of a $\beta$-Tricalcium Phosphate Scaffold and Bone Marrow Stromal Cells in a Non-Human Primate Model. Open Biomed. Eng. J. 10, 2-11. doi:10.2174/ 1874120701610010002

Matsunaga, K., Kubota, T., Toyoura, K., and Nakamura, A. (2015). First-principles Calculations of Divalent Substitution of $\mathrm{Ca}(2+)$ in Tricalcium Phosphates. Acta Biomater. 23, 329-337. doi:10.1016/j.actbio.2015.05.014

Meka, S. R. K., Agarwal, V., and Chatterjee, K. (2019). In Situ preparation of Multicomponent Polymer Composite Nanofibrous Scaffolds with Enhanced Osteogenic and Angiogenic Activities. Mater. Sci. Eng. C, Mater. Biol. Appl. 94, 565-579. doi:10.1016/j.msec.2018.09.055

Mihalyi, E. (1988). Clotting of Bovine Fibrinogen. Kinetic Analysis of the Release of Fibrinopeptides by Thrombin and of the Calcium Uptake upon Clotting at High Fibrinogen Concentrations. Biochemistry 27, 976-982. doi:10.1021/ bi00403a021

Mijiritsky, E., Assaf, H. D., Peleg, O., Shacham, M., Cerroni, L., and Mangani, L. (2021). Use of PRP, PRF and CGF in Periodontal Regeneration and Facial Rejuvenation-A Narrative Review. Biology 10, 317. doi:10.3390/ biology 10040317

Milleret, V., Buzzi, S., Gehrig, P., Ziogas, A., Grossmann, J., Schilcher, K., et al. (2015). Protein Adsorption Steers Blood Contact Activation on Engineered Cobalt Chromium alloy Oxide Layers. Acta Biomater. 24, 343-351. doi:10.1016/ j.actbio.2015.06.020

Moccia, F., Berra-Romani, R., and Tanzi, F. (2012). Update on Vascular Endothelial $\mathrm{Ca}(2+)$ Signalling: A Tale of Ion Channels, Pumps and Transporters. World J. Biol. Chem. 3, 127-158. doi:10.4331/wjbc.v3.i7.127

Moccia, F., Tanzi, F., and Munaron, L. (2014). Endothelial Remodelling and Intracellular Calcium Machinery. Curr. Mol. Med. 14, 457-480. doi:10.2174/ 1566524013666131118113410

Mochizuki, M., Güç, E., Park, A. J., Julier, Z., Briquez, P. S., Kuhn, G. A., et al. (2020). Growth Factors with Enhanced Syndecan Binding Generate Tonic Signalling and Promote Tissue Healing. Nat. Biomed. Eng. 4, 463-475. doi:10.1038/s41551-019-0469-1

Morrissey, J. H., and Smith, S. A. (2015). Polyphosphate as Modulator of Hemostasis, Thrombosis, and Inflammation. J. Thromb. Haemost. 13 (Suppl. 1), S92-S97. doi:10.1111/jth.12896

Muller, F., Mutch, N. J., Schenk, W. A., Smith, S. A., Esterl, L., Spronk, H. M., et al. (2009). Platelet Polyphosphates Are Proinflammatory and Procoagulant Mediators In Vivo. Cell 139, 1143-1156. doi:10.1016/j.cell.2009.11.001

Muszbek, L., Bereczky, Z., Bagoly, Z., Komáromi, I., and Katona, É. (2011). Factor XIII: a Coagulation Factor with Multiple Plasmatic and Cellular Functions. Physiol. Rev. 91, 931-972. doi:10.1152/physrev.00016.2010

Mutch, N. J. (2016). Polyphosphate as a Haemostatic Modulator. Biochem. Soc. Trans. 44, 18-24. doi:10.1042/bst20150207

Nagaraja, S., Mathew, S., Abraham, A., Ramesh, P., and Chandanala, S. (2020). Evaluation of Vascular Endothelial Growth Factor - A Release from Platelet-Rich Fibrin, Platelet-Rich Fibrin Matrix, and Dental Pulp at Different Time Intervals. J. Conser. Dent. 23, 359-363. doi:10.4103/ jcd.Jcd_465_19

Nakamura, S., Matsumoto, T., Sasaki, J., Egusa, H., Lee, K. Y., Nakano, T., et al. (2010). Effect of Calcium Ion Concentrations on Osteogenic Differentiation 
and Hematopoietic Stem Cell Niche-Related Protein Expression in Osteoblasts. Tissue Eng. Part. A. 16, 2467-2473. doi:10.1089/ten.TEA.2009.0337

Nandi, S. K., Fielding, G., Banerjee, D., Bandyopadhyay, A., and Bose, S. (2018). 3D Printed Beta-TCP Bone Tissue Engineering Scaffolds: Effects of Chemistry on In Vivo Biological Properties in a Rabbit Tibia Model. J. Mater. Res. 33, 1939-1947. doi:10.1557/jmr.2018.233

Nguyen, L. H., Annabi, N., Nikkhah, M., Bae, H., Binan, L., Park, S., et al. (2012). Vascularized Bone Tissue Engineering: Approaches for Potential Improvement. Tissue Eng. Part. B, Rev. 18, 363-382. doi:10.1089/ten.TEB.2012.0012

Ni, X., Shan, X., Xu, L., Yu, W., Zhang, M., Lei, C., et al. (2021). Adipose-derived Stem Cells Combined with Platelet-Rich Plasma Enhance Wound Healing in a Rat Model of Full-Thickness Skin Defects. Stem Cel. Res. Ther. 12, 226. doi:10.1186/s13287-021-02257-1

Odrljin, T. M., Rybarczyk, B. J., Francis, C. W., Lawrence, S. O., Hamaguchi, M., and Simpson-Haidaris, P. J. (1996). Calcium Modulates Plasmin Cleavage of the Fibrinogen D Fragment Gamma Chain N-Terminus: Mapping of Monoclonal Antibody J88B to a Plasmin Sensitive Domain of the Gamma Chain. Biochim. Biophys. Acta 1298, 69-77. doi:10.1016/s0167-4838(96) 00090-8

Ozerdem, B. (2002). Tensile Adhesion of Type I Collagen to Titanium alloy and Calcium Phosphate Coated Surfaces with Different Roughness Values. Biomedical Mater. Eng. 12, 347-352.

Pennati, A., Apfelbeck, T., Brounts, S., and Galipeau, J. (2020). Washed Equine Platelet Extract as an Anti-Inflammatory Biologic Pharmaceutical. Tissue Eng. Part. A. doi:10.1089/ten.TEA.2020.0160

Pereira, R. S., Gorla, L. F., Boos, F. B. J. D., Okamoto, R., Garcia Júnior, I. R., and Hochuli-Vieira, E. (2017). Use of Autogenous Bone and Beta-Tricalcium Phosphate in Maxillary Sinus Lifting: Histomorphometric Study and Immunohistochemical Assessment of RUNX2 and VEGF. Int. J. Oral Maxillofac. Surg. 46, 503-510. doi:10.1016/j.ijom.2017.01.002

Piechocka, I. K., Kurniawan, N. A., Grimbergen, J., Koopman, J., and Koenderink, G. H. (2017). Recombinant Fibrinogen Reveals the Differential Roles of $\alpha$ - and $\gamma$-chain Cross-Linking and Molecular Heterogeneity in Fibrin Clot StrainStiffening. J. Thromb. Haemost. 15, 938-949. doi:10.1111/jth.13650

Pilliar, R. M., Filiaggi, M. J., Wells, J. D., Grynpas, M. D., and Kandel, R. A. (2001). Porous Calcium Polyphosphate Scaffolds for Bone Substitute Applications -- In Vitro Characterization. Biomaterials 22, 963-972. doi:10.1016/s0142-9612(00) 00261-1

Protopopova, A. D., Ramirez, A., Klinov, D. V., Litvinov, R. I., and Weisel, J. W. (2019). Factor XIII Topology: Organization of B Subunits and Changes with Activation Studied with Single-Molecule Atomic Force Microscopy. J. Thromb. Haemost. 17, 737-748. doi:10.1111/jth.14412

Putri, T. S., Hayashi, K., and Ishikawa, K. (2020). Bone Regeneration Using BetaTricalcium Phosphate (Beta-TCP) Block with Interconnected Pores Made by Setting Reaction of Beta-TCP Granules. J. Biomed. Mater. Res. Part A. 108, 625-632. doi:10.1002/jbm.a.36842

Qiao, J., An, N., and Ouyang, X. (2017). Quantification of Growth Factors in Different Platelet Concentrates. Platelets 28, 774-778. doi:10.1080/ 09537104.2016.1267338

Raeisdasteh Hokmabad, V., Davaran, S., Ramazani, A., and Salehi, R. (2017). Design and Fabrication of Porous Biodegradable Scaffolds: a Strategy for Tissue Engineering. J. Biomater. Sci. Polym. Ed. 28, 1797-1825. doi:10.1080/ 09205063.2017.1354674

Rahmany, M. B., Hantgan, R. R., and Van Dyke, M. (2013). A Mechanistic Investigation of the Effect of Keratin-Based Hemostatic Agents on Coagulation. Biomaterials 34, 2492-2500. doi:10.1016/ j.biomaterials.2012.12.008

Rather, H. A., Jhala, D., and Vasita, R. (2019). Dual Functional Approaches for Osteogenesis Coupled Angiogenesis in Bone Tissue Engineering. Mater. Sci. Eng. C, Mater. Biol. Appl. 103, 109761. doi:10.1016/j.msec.2019.109761

Reid, J. W., Pietak, A., Sayer, M., Dunfield, D., and Smith, T. J. (2005). Phase Formation and Evolution in the Silicon Substituted Tricalcium Phosphate/ apatite System. Biomaterials 26, 2887-2897. doi:10.1016/ j.biomaterials.2004.09.005

Robering, J. W., Al-Abboodi, M., Titzmann, A., Horn, I., Beier, J. P., Horch, R. E., et al. (2021). Tissue Engineering of Lymphatic Vasculature in the Arteriovenous Loop Model of the Rat. Tissue Eng. Part A 27, 129-141. doi:10.1089/ ten.TEA.2020.0108
Roopavath, U. K., Sah, M. K., Panigrahic, B. B., and Ratha, S. N. (2019). Mechanochemically Synthesized Phase Stable and Biocompatible $\beta$ tricalcium Phosphate from Avian Eggshell for the Development of Tissue Ingrowth System. Ceramics Int. 45, 12910-12919. doi:10.1016/j.ceramint.2019.03.217

Ruiz, F. A., Lea, C. R., Oldfield, E., and Docampo, R. (2004). Human Platelet Dense Granules Contain Polyphosphate and Are Similar to Acidocalcisomes of Bacteria and Unicellular Eukaryotes. J. Biol. Chem. 279, 44250-44257. doi:10.1074/jbc.M406261200

Rustom, L. E., Poellmann, M. J., and Wagoner Johnson, A. J. (2019). Mineralization in Micropores of Calcium Phosphate Scaffolds. Acta Biomater. 83, 435-455. doi:10.1016/j.actbio.2018.11.003

Seidenstuecker, M., Kerr, L., Bernstein, A., Mayr, H. O., Suedkamp, N. P., Gadow, R., et al. (2017). 3D Powder Printed Bioglass and Beta-Tricalcium Phosphate Bone Scaffolds. Materials (Basel) 11, 13. doi:10.3390/ma11010013

Seidenstuecker, M., Lange, S., Esslinger, S., Latorre, S. H., Krastev, R., Gadow, R., et al. (2019). Inversely 3D-Printed $\beta$-TCP Scaffolds for Bone Replacement. Materials (Basel) 12, 3417. doi:10.3390/ma12203417

Sen, S., Diercke, K., Zingler, S., Lux, C. J., and Erber, R. (2015). Compression Induces Ephrin-A2 in PDL Fibroblasts via C-Fos. J. Dent. Res. 94, 464-472. doi:10.1177/0022034514567197

Seong, Y. J., Song, E. H., Park, C., Lee, H., Kang, I. G., Kim, H. E., et al. (2020). Porous Calcium Phosphate-Collagen Composite Microspheres for Effective Growth Factor Delivery and Bone Tissue Regeneration. Mater. Sci. Eng. C, Mater. Biol. Appl. 109, 110480. doi:10.1016/j.msec.2019.110480

Shainoff, J. R., Urbanic, D. A., and DiBello, P. M. (1991). Immunoelectrophoretic Characterizations of the Cross-Linking of Fibrinogen and Fibrin by Factor XIIIa and Tissue Transglutaminase. Identification of a Rapid Mode of Hybrid Alpha-/gamma-Chain CrossLinking that Is Promoted by the Gamma-Chain Cross-Linking. J. Biol. Chem. 266, 6429-6437. doi:10.1016/s0021-9258(18)38136-5

Singh, S., Dodt, J., Volkers, P., Hethershaw, E., Philippou, H., Ivaskevicius, V., et al. (2019). Structure Functional Insights into Calcium Binding during the Activation of Coagulation Factor XIII A. Sci. Rep. 9, 11324. doi:10.1038/ s41598-019-47815-Z

Smith, S. A., and Morrissey, J. H. (2008). Polyphosphate Enhances Fibrin Clot Structure. Blood 112, 2810-2816. doi:10.1182/blood-2008-03-145755

Smith, S. A., and Morrissey, J. H. (2014). Polyphosphate: a New Player in the Field of Hemostasis. Curr. Opin. Hematol. 21, 388-394. doi:10.1097/ moh.0000000000000069

Spraggon, G., Everse, S. J., and Doolittle, R. F. (1997). Crystal Structures of Fragment D from Human Fibrinogen and its Crosslinked Counterpart from Fibrin. Nature 389, 455-462. doi:10.1038/38947

Standeven, K. F., Carter, A. M., Grant, P. J., Weisel, J. W., Chernysh, I., Masova, L., et al. (2007). Functional Analysis of Fibrin \{gamma\}-Chain Cross-Linking by Activated Factor XIII: Determination of a Cross-Linking Pattern that Maximizes Clot Stiffness. Blood 110, 902-907. doi:10.1182/blood-2007-01-066837

Stastny, P., Sedlacek, R., Suchy, T., Lukasova, V., Rampichova, M., and Trunec, M. (2019). Structure Degradation and Strength Changes of Sintered Calcium Phosphate Bone Scaffolds with Different Phase Structures during Simulated Biodegradation In Vitro. Mater. Sci. Eng. C, Mater. Biol. Appl. 100, 544-553. doi:10.1016/j.msec.2019.03.027

Tan, Y. Z., Fei, D. D., He, X. N., Dai, J. M., Xu, R. C., Xu, X. Y., et al. (2019). L-type Voltage-Gated Calcium Channels in Stem Cells and Tissue Engineering. Cel Prolif. 52, e12623. doi:10.1111/cpr.12623

Tanaka, T., Kumagae, Y., Saito, M., Chazono, M., Komaki, H., Kikuchi, T., et al. (2008). Bone Formation and Resorption in Patients after Implantation of BetaTricalcium Phosphate Blocks with 60\% and 75\% Porosity in Opening-Wedge High Tibial Osteotomy. J. Biomed. Mater. Res. B, Appl. Biomater. 86, 453-459. doi:10.1002/jbm.b.31041

Varin, R., Mirshahi, S., Mirshahi, P., Klein, C., Jamshedov, J., Chidiac, J., et al. (2013). Whole Blood Clots Are More Resistant to Lysis Than Plasma ClotsGgreater Efficacy of Rivaroxaban. Thromb. Res. 131, e100. doi:10.1016/ j.thromres.2012.11.029

Vasilyeva, A., Yurina, L., Indeykina, M., Bychkova, A., Bugrova, A., Biryukova, M., et al. (2018). Oxidation-induced Modifications of the Catalytic Subunits of Plasma Fibrin-Stabilizing Factor at the Different Stages of its Activation Identified by Mass Spectrometry. Biochim. Biophys. Acta Proteins Proteom. 1866, 875-884. doi:10.1016/j.bbapap.2018.05.001 
Wagner, E. F. (2002). Functions of AP1 (Fos/Jun) in Bone Development. Ann. Rheum. Dis. 61 (Suppl. 2), ii40. doi:10.1136/ard.61.suppl_2.ii40

Wang, C., Yue, H., Liu, J., Zhao, Q., He, Z., Li, K., et al. (2020b). Advanced Reconfigurable Scaffolds Fabricated by 4D Printing for Treating Critical-Size Bone Defects of Irregular Shapes. Biofabrication 12, 045025. doi:10.1088/17585090/abab5b

Wang, G., Roohani-Esfahani, S. I., Zhang, W., Lv, K., Yang, G., Ding, X., et al. (2017a). Effects of Sr-HT-Gahnite on Osteogenesis and Angiogenesis by Adipose Derived Stem Cells for Critical-Sized Calvarial Defect Repair. Scientific Rep. 7, 41135. doi:10.1038/srep41135

Wang, J. Q., Jiang, B. J., Guo, W. J., and Zhao, Y. M. (2019a). Indirect 3D Printing Technology for the Fabrication of Customised Beta-TCP/chitosan Scaffold with the Shape of Rabbit Radial Head-An In Vitro Study. J. Orthop. Surg. Res. 14, 102. doi:10.1186/s13018-019-1136-7

Wang, K., Li, Z., Li, J., Liao, W., Qin, Y., Zhang, N., et al. (2019b). Optimization of the Platelet-Rich Plasma Concentration for Mesenchymal Stem Cell Applications. Tissue Eng. Part. A. 25, 333-351. doi:10.1089/ten.TEA.2018.0091

Wang, L., Lan, Y., Du, Y., Xiang, X., Tian, W., Yang, B., et al. (2020c). Plastin 1 Promotes Osteoblast Differentiation by Regulating Intracellular Ca2. Acta Biochim. Biophys. Sinica 52, 563-569. doi:10.1093/abbs/gmaa027

Wang, W., and Yeung, K. W. K. (2017). Bone Grafts and Biomaterials Substitutes for Bone Defect Repair: A Review. Bioact Mater. 2, 224-247. doi:10.1016/ j.bioactmat.2017.05.007

Wang, X., Friis, T. E., Masci, P. P., Crawford, R. W., Liao, W., and Xiao, Y. (2016). Alteration of Blood Clot Structures by Interleukin-1 Beta in Association with Bone Defects Healing. Scientific Rep. 6, 35645. doi:10.1038/srep35645

Wang, X., Friis, T., Glatt, V., Crawford, R., and Xiao, Y. (2017b). Structural Properties of Fracture Haematoma: Current Status and Future Clinical Implications. J. Tissue Eng. Regen. Med. 11, 2864-2875. doi:10.1002/term.2190

Wang, X., Luo, Y., Yang, Y., Zheng, B., Yan, F., Wei, F., et al. (2018a). Alteration of Clot Architecture Using Bone Substitute Biomaterials (Beta-tricalcium Phosphate) Significantly Delays the Early Bone Healing Process. J. Mater. Chem. B. 6, 8204-8213. doi:10.1039/c8tb01747f

Wang, X., Zhang, Y., Choukroun, J., Ghanaati, S., and Miron, R. J. (2018b). Effects of an Injectable Platelet-Rich Fibrin on Osteoblast Behavior and Bone Tissue Formation in Comparison to Platelet-Rich Plasma. Platelets 29, 48-55. doi:10.1080/09537104.2017.1293807

Wang, Z., Liu, Q., Liu, C., Tan, W., Tang, M., Zhou, X., et al. (2020a). $\mathrm{Mg}(2+)$ in $\beta$-TCP/Mg-Zn Composite Enhances the Differentiation of Human Bone Marrow Stromal Cells into Osteoblasts through MAPK-Regulated Runx2/ Osx. J. Cell. Physiol. 235, 5182-5191. doi:10.1002/jcp.29395

Wang, Z., Weng, Y., Lu, S., Zong, C., Qiu, J., Liu, Y., et al. (2015). Osteoblastic Mesenchymal Stem Cell Sheet Combined with Choukroun Platelet-Rich Fibrin Induces Bone Formation at an Ectopic Site. J. Biomed. Mater. Res. B, Appl. Biomater. 103, 1204-1216. doi:10.1002/jbm.b.33288

Weisel, J. W., and Litvinov, R. I. (2017). Fibrin Formation, Structure and Properties. Subcell. Biochem. 82, 405-456. doi:10.1007/978-3-319-49674-0_13 Weisel, J. W., and Litvinov, R. I. (2013). Mechanisms of Fibrin Polymerization and Clinical Implications. Blood 121, 1712-1719. doi:10.1182/blood-2012-09-306639

Wen, L., Wang, Y., Wang, H., Kong, L., Zhang, L., Chen, X., et al. (2012). L-type Calcium Channels Play a Crucial Role in the Proliferation and Osteogenic Differentiation of Bone Marrow Mesenchymal Stem Cells. Biochem. Biophys. Res. Commun. 424, 439-445. doi:10.1016/j.bbrc.2012.06.128

Whyte, C. S., Chernysh, I. N., Domingues, M. M., Connell, S., Weisel, J. W., Ariens, R. A., et al. (2016). Polyphosphate Delays Fibrin Polymerisation and Alters the Mechanical Properties of the Fibrin Network. Thromb. Haemost. 116, 897-903. doi:10.1160/th16-01-0062

Wu, T., Shi, H., Liang, Y., Lu, T., Lin, Z., and Ye, J. (2020). Improving Osteogenesis of Calcium Phosphate Bone Cement by Incorporating with Manganese Doped $\beta$-tricalcium Phosphate. Mater. Sci. Eng. C, Mater. Biol. Appl. 109, 110481. doi:10.1016/j.msec.2019.110481

Xie, L., Yu, H., Deng, Y., Yang, W., Liao, L., and Long, Q. (2016). Preparation, Characterization and In Vitro Dissolution Behavior of Porous Biphasic $\alpha / \beta$-tricalcium Phosphate Bioceramics. Mater. Sci. Eng. C, Mater. Biol. Appl. 59, 1007-1015. doi:10.1016/j.msec.2015.11.040
Xie, Z., Yan, D., Zhou, Q., Wu, Z., Weng, S., Boodhun, V., et al. (2019). The Fast Degradation of Beta-TCP Ceramics Facilitates Healing of Bone Defects by the Combination of BMP-2 and Teriparatide. Biomed. Pharmacother. 112, 108578. doi:10.1016/j.biopha.2019.01.039

Yassuda, D. H., Costa, N. F., Fernandes, G. O., Alves, G. G., Granjeiro, J. M., and Soares Gde, A. (2013). Magnesium Incorporation into Beta-TCP Reduced its In Vivo Resorption by Decreasing Parathormone Production. J. Biomed. Mater. Res. Part A. 101, 1986-1993. doi:10.1002/jbm.a.34502

Yermolenko, I. S., Lishko, V. K., Ugarova, T. P., and Magonov, S. N. (2011). High-resolution Visualization of Fibrinogen Molecules and Fibrin Fibers with Atomic Force Microscopy. Biomacromolecules 12, 370-379. doi:10.1021/bm101122g

Ying, C., Wang, R., Wang, Z., Tao, J., Yin, W., Zhang, J., et al. (2020). BMSCExosomes Carry Mutant HIF-1 $\alpha$ for Improving Angiogenesis and Osteogenesis in Critical-Sized Calvarial Defects. Front. Bioeng. Biotechnol. 8, 565561. doi:10.3389/fbioe.2020.565561

Yuan, J., Wang, B., Han, C., Huang, X., Xiao, H., Lu, X., et al. (2020). Nanosized-Ag-doped Porous $\beta$-tricalcium Phosphate for Biological Applications. Mater. Sci. Eng. C, Mater. Biol. Appl. 114, 111037. doi:10.1016/j.msec.2020.111037

Zamani, Y., Amoabediny, G., Mohammadi, J., Zandieh-Doulabi, B., Klein-Nulend, J., and Helder, M. N. (2021). Increased Osteogenic Potential of Pre-Osteoblasts on Three-Dimensional Printed Scaffolds Compared to Porous Scaffolds for Bone Regeneration. Iranian Biomed. J. 25, 78-87. doi:10.29252/ibj.25.2.78

Zayzafoon, M., Fulzele, K., and McDonald, J. M. (2005). Calmodulin and Calmodulin-dependent Kinase IIalpha Regulate Osteoblast Differentiation by Controlling C-Fos Expression. J. Biol. Chem. 280, 7049-7059. doi:10.1074/jbc.M412680200

Zeng, Q., Zhou, Z., Qin, S., Yao, Y., Qin, J., Zhang, H., et al. (2020). Rapamycin Inhibits B-Cell Activating Factor (BAFF)-stimulated Cell Proliferation and Survival by Suppressing $\mathrm{Ca}(2+)$-CaMKII-dependent PTEN/Akt-Erk1/2 Signaling Pathway in normal and Neoplastic B-Lymphoid Cells. Cell Calcium 87, 102171. doi:10.1016/j.ceca.2020.102171

Zhang, J., Liu, X., Li, H., Chen, C., Hu, B., Niu, X., et al. (2016). Exosomes/ tricalcium Phosphate Combination Scaffolds Can Enhance Bone Regeneration by Activating the PI3K/Akt Signaling Pathway. Stem Cel. Res. Ther. 7, 136. doi:10.1186/s13287-016-0391-3

Zhang, J. T., Zhang, S. S., Liu, C. G., Kankala, R. K., Chen, A. Z., and Wang, S. B. (2021). Low-temperature Extrusion-Based 3D Printing of Icariin-Laden Scaffolds for Osteogenesis Enrichment. Regen. Ther. 16, 53-62. doi:10.1016/ j.reth.2021.01.001

Zhang, J., Wu, H., He, F., Wu, T., Zhou, L., and Ye, J. (2019). Concentrationdependent Osteogenic and Angiogenic Biological Performances of Calcium Phosphate Cement Modified with Copper Ions. Mater. Sci. Eng. C, Mater. Biol. Appl. 99, 1199-1212. doi:10.1016/j.msec.2019.02.042

Zhao, H., Yeersheng, R., Xia, Y., Kang, P., and Wang, W. (2021). Hypoxia Enhanced Bone Regeneration Through the HIF-1 $\alpha / \beta$-Catenin Pathway in Femoral Head Osteonecrosis. Am. J. Med. Sci. doi:10.1016/ j.amjms.2021.03.005

Zheng, Z.-w., Chen, Y.-h., Wu, D.-y., Wang, J.-b., Lv, M.-m., Wang, X.-s., et al. (2018). Development of an Accurate and Proactive Immunomodulatory Strategy to Improve Bone Substitute Material-Mediated Osteogenesis and Angiogenesis. Theranostics 8, 5482-5500. doi:10.7150/thno.28315

Conflict of Interest: The authors declare that the research was conducted in the absence of any commercial or financial relationships that could be construed as a potential conflict of interest.

Copyright $\odot 2021 \mathrm{Lu}$, Zhou, Ma, Xiao, Ji, Zhang and Wang. This is an open-access article distributed under the terms of the Creative Commons Attribution License (CC $B Y$ ). The use, distribution or reproduction in other forums is permitted, provided the original author(s) and the copyright owner(s) are credited and that the original publication in this journal is cited, in accordance with accepted academic practice. No use, distribution or reproduction is permitted which does not comply with these terms. 